\title{
User's Characteristics and Its Role in the Diffusion of Health Information Technology in the Private Hospitals in Dohuk
}

Journal of

\section{TANMIYAT AL- RAFIDAIN}

\section{(TANRA)}

A scientific, quarterly, international, open access, and peer-reviewed journal

Vol. 39, No. 128

Dec., 2020

(C) University of Mosul | College of Administration and Economics, Mosul, Iraq.

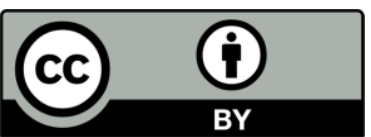

TANRA retain the copyright of published articles, which is released under a "Creative Commons Attribution License for CC-BY-4.0" enabling the unrestricted use, distribution, and reproduction of an article in any medium, provided that the original work is properly cited.

Citation: Taha, Tuqa A. and Ahmed Y. Sabawi (2020). “User's Characteristics and Its Role in the Diffusion of Health Information Technology in the Private Hospitals in Dohuk". TANMIYAT ALRAFIDAIN, 39 (128), 150-172, https://doi.org/10.33899/tanra.20 20.167373

P-ISSN: 1609-591X e-ISSN: 2664-276X tanmiyat.mosuljournals.com
Tuqa A. Taha ${ }^{1}$; Ahmed Y. Sabawi ${ }^{2}$

$1 \& 2$ College of Administration and Economics; University of Mosul

Corresponding author: Tuqa A. Taha, tukaabdalnafie@yahoo.com

DOI: 10.33899/tanra.2020.167373

Article History: Received: 12/8/2020; Revised: 27/6/2020; Accepted: 12/8/2020; Published: $1 / 12 / 2020$.

\section{Abstract}

The diffusion of health information technology (IT) is still one of the most important issues in this sector. The main reason behind this issue is that health IT is employed in an institutional environment characterized by high technical complexity, and this makes the processes of change towards the adoption and diffusion of health IT are difficult, especially with resisting change by some staff are working in health institutions. The current study came to identify the user's characteristics that impact the diffusion of IT. The study has been designed based on the literature of information systems and includes four constructs: personal innovativeness, self-efficacy, the user's attitude towards technology, and trust in information technology. Concerning the sample, it included the health staff working in six private hospitals in the city of Dohuk, and a questionnaire was built based on the previous studies as a tool to collect data, and the number of study sample individuals was (233). The main result of the study is that there is a significant effect of user characteristics (at the level of each characteristic and at the macro level) on the diffusion of health IT. This result is prove that the process of diffusion IT applications depends mainly on the characteristics obtained by users that support the diffusion process. The study recommends to pay more attention to the user's characteristics, such as personal Innovations, enhancing his self-efficacy, contributing to building his positive attitude towards technology and enhancing the trust in IT, due to its role in diffusing the health IT.

\section{Key words:}

IT health, User's characteristics, Personal innovativeness, Self-efficacy, User attitude, IT Trust. 


\section{ورقة بحثية \\ خصائص المستفيد ودورها في انتشار تقانة المعلومات

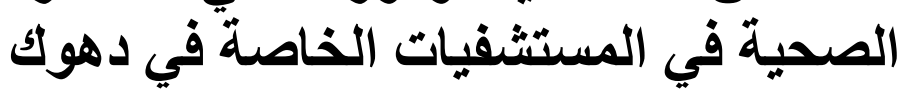

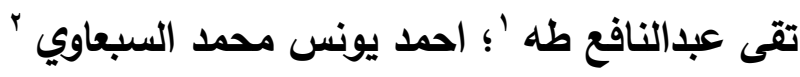

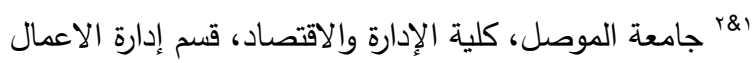

DOI: 10.33899/tanra.2020.167373

tukaabdalnafie@yahoo.com ، المؤلف المراسل: تقى عبالنافع طه

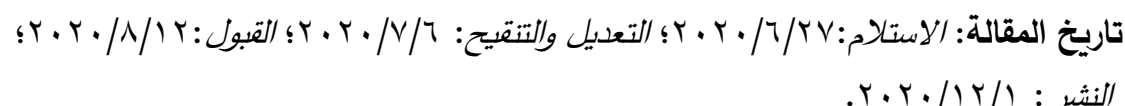

المستخلص

تمثل مسألة انتشار تقانة الدعلومات الصحية احدى أهم القضايا في هذا القطاع، والسبب يعود إلى ان

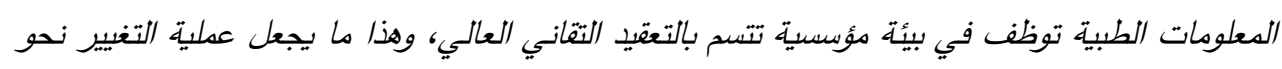

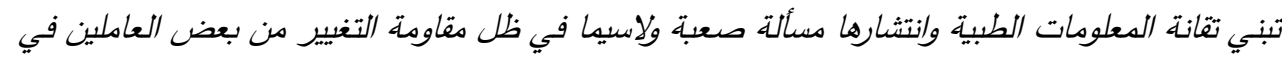

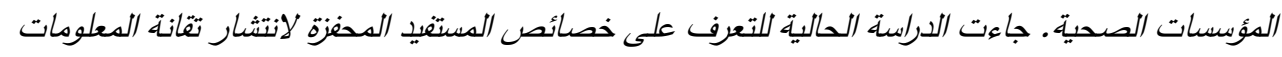

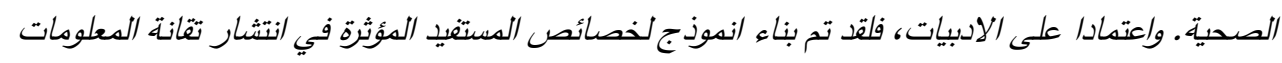

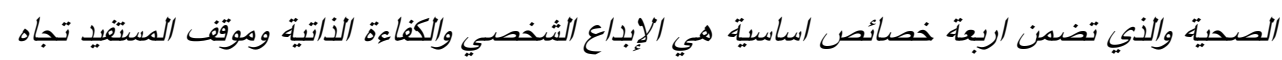

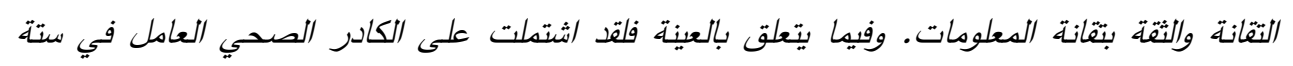

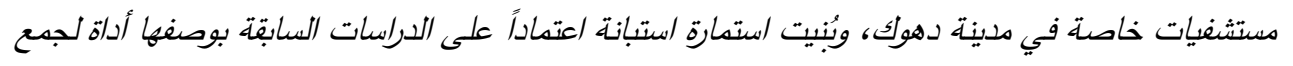

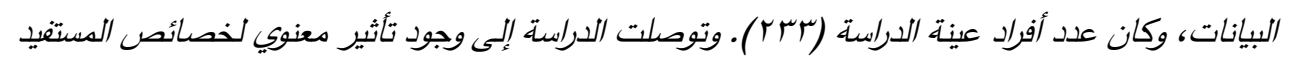

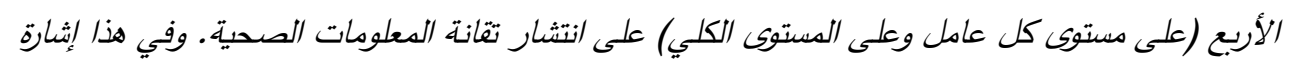

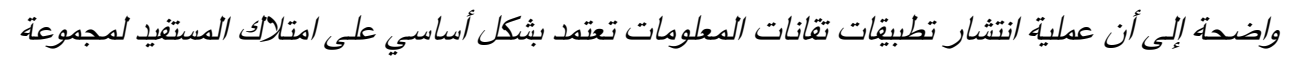

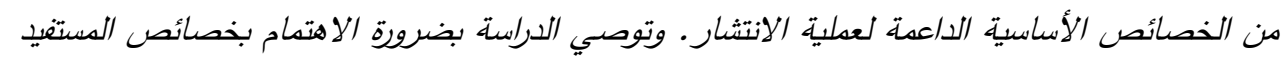
كالإبداع الشخصي وتعزيز الكفاءة الذاتية لديه، والإسهام في بناء موقفه الإيجابي تجاه التقانة، وتدعيم ثقته الأنه

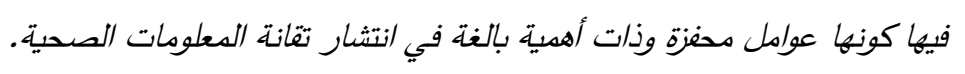

الكلمات المفتاحية

تقانة المعلومات الصحية، خصائص المستفيد، الإبداع الشخصي، الكفاءة الأتية، موقف المستفيد، الثقة بتقانة المعلومات.

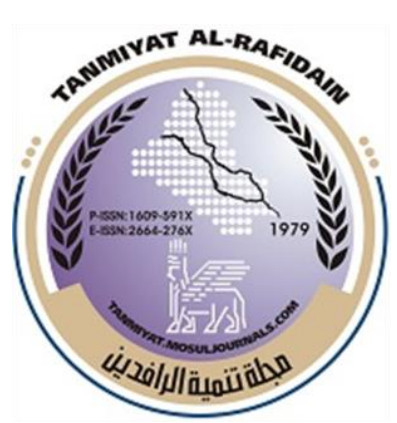

\section{هبلة}

\section{تنمية الرافدين}

دولة (TANRA) دولية، مفتوحة الوصول، محكمة.

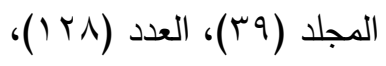

$$
\begin{aligned}
& \text { كانون الاول .r.r. }
\end{aligned}
$$

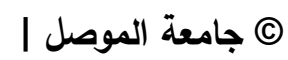
كلية الإدارة والاقتصاد، الموصل، العرله

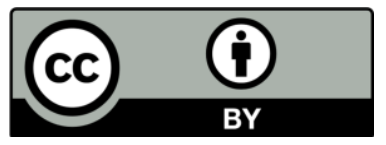

تحتظظ (TANRA) بحقوق الطبع والنشر للمقالات

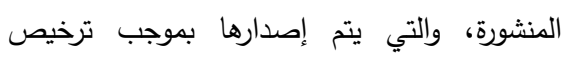
ل(Creative Commons Attribution) (CC-BY-4.0) والاستنساخ غير المقيد وتوزيع للمقالة في أي وسيط الأني نقل، بشرط اقتباس العمل الأصلي بشكل صحيح.

الاقتباس: طه، تقى عبالنافع و السبعاوي

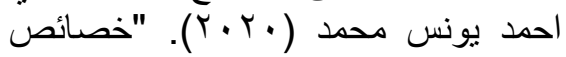
المستفيد ودور ها في انتشار تقانة المعلومات المدات

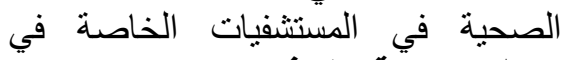

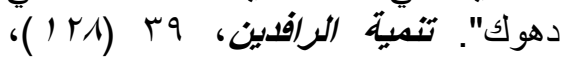
6) VY-10. https://doi.org/10.33899/tanra.20 20.167373

P-ISSN: 1609-591X e-ISSN: 2664-276X tanmiyat.mosuljournals.com 
المحور الأول: المقدمة

لقد أضحى لتقانة المعلومات دور ذو أهمية خاصة في المجال الصحي، إذ إن التطورات في مجال

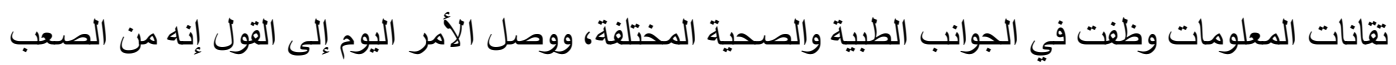
ممارسة الطب بدون الاستعانة بتقانة المعلومات الطبية المتطورة. وقد تطور الحال في هذا القطاع، فضلاً عن التطور العلمي في الجانب الطبي، ليشمل ظهور أنظمة معلومات طبية تعمل وفق التقانة المعلوماتية التي لها دور كبير وفعال في مجال إدارة المعلومات الصحية والطبية، ومن أهم هذه التطبيقات نظم إدارة معلومات المستثفيات والتطبيب عن بعد ونظم دعم القرار الطبي والإداري، والرعاية الصحية الإكترونية. وفي خضم ذلك وعند النظر في التطورات الحاصلة بالقطاع نفسه وبخاصة على صعيد الأجهزة والمعدات

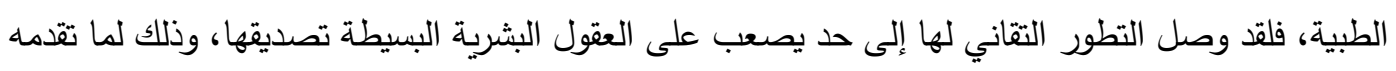
من إمكانيات تقانية كبرى امتدت إلى قدرتها العلاجية من دون استعمال اليد أو الملامسة، وهو ما لمانية عرفناه

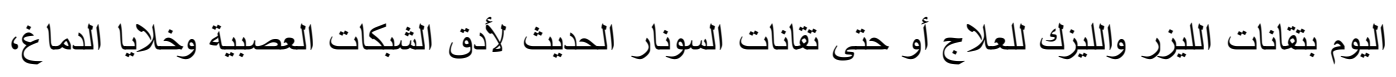
ناهيك عن الاستعمال الدقيق لأدوات تقانية تستعمل في الأماكن الصعبة جداً مثل الثرايين والأوردة الدموية.

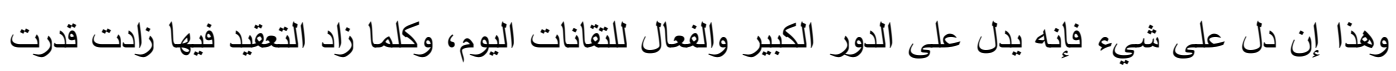
القطاع على التقدم والنهوض بواقع صحي أفضل (Aluzir, 2018, 2). إن اعتماد تقانة المعلومات الصحية يتطلب إنفاقاً عالياً على هذا المجال، ولقد أشارت دراسة (2018) Wilson \& Khansa إلى أن أن الولايات

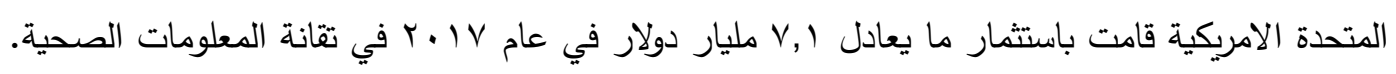

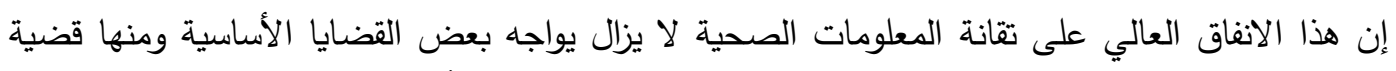

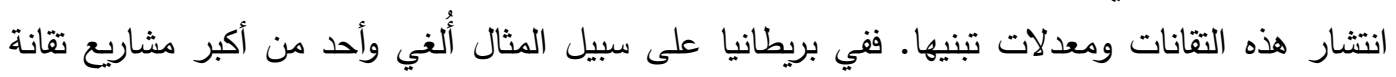

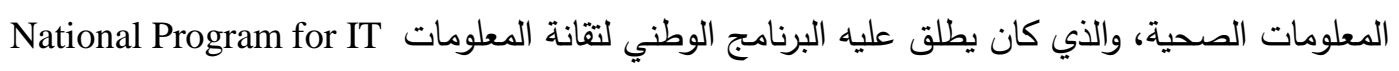

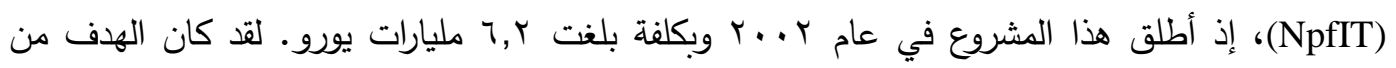
المشروع هو رقمنة Digitilzation الرعاية الصحية في الخدمة الصحية الوطنية بإنجلترا ، وذلك من خلال إدخال أنظمة إلكترونية متكاملة في القطاع الصحي، ومن ثم تحسين جودة الخدمات والرعاية الصحية المقدمة

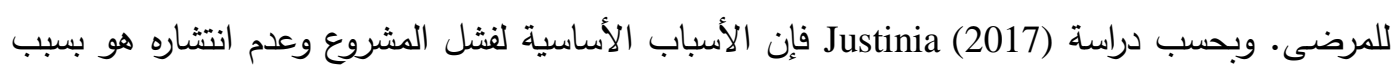

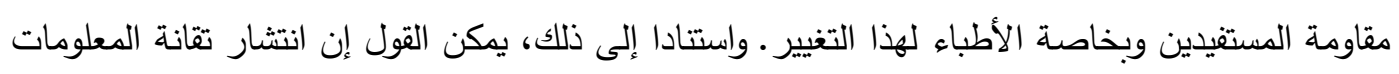

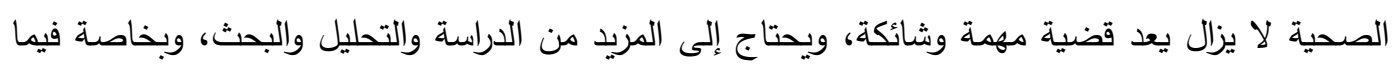

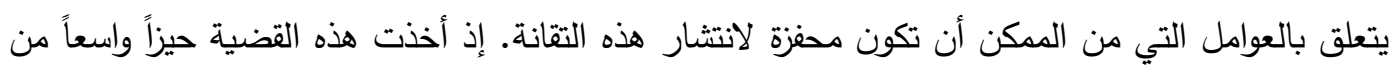

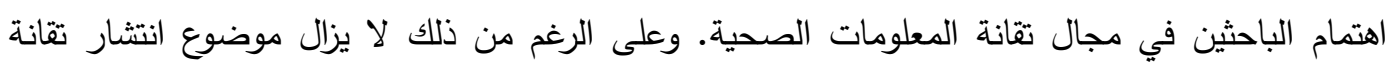

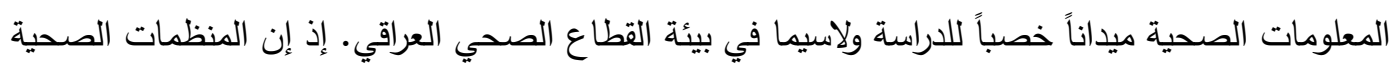

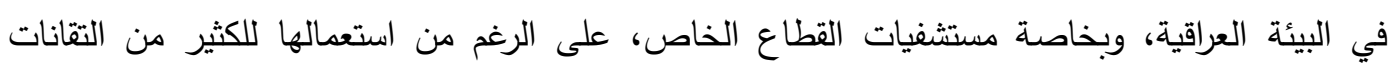


المتطورة، إلا أنه مازال هناك حاجة لمعرفة أهم خصائص المستثيد المحفزة لانتثار تقانات المعلومات الصحية

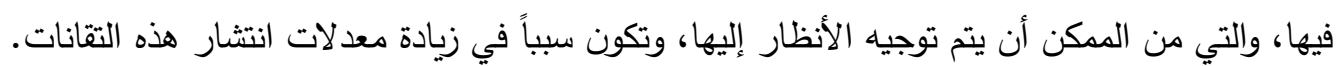

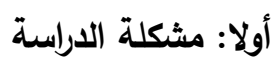

لقد لاقت تقانة المعلومات الطبية رواجاً وانتشاراً واسعاً، وذلك للمنافع المستحصلة دنها في دعم العمل

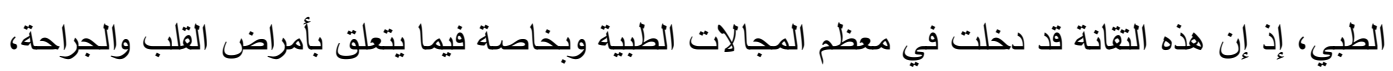
وكذلك الحال بالنسبة للمختبرات الطبية وأجهزة الفحص والأشعة والسونار ـ وعلى الرغم من ذلك هناك مشكلة الطنة

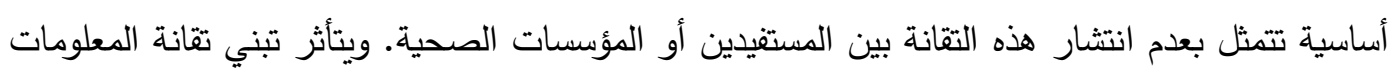

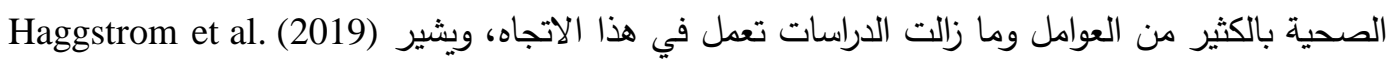

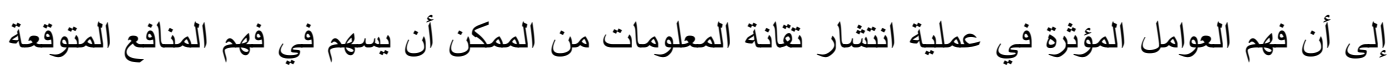

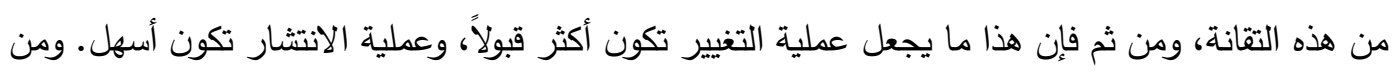

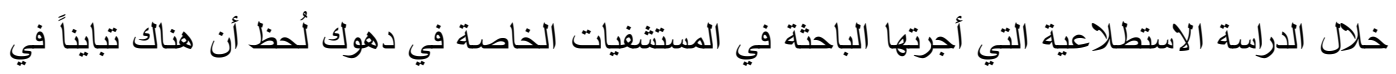

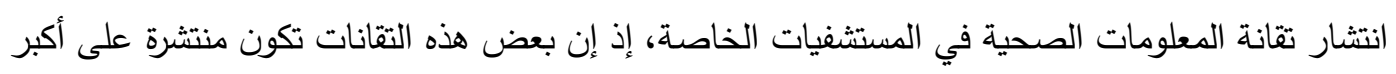
نطاق، في حين إن البعض الآخر منها لا يكاد يذكر إلا في مستشفيات محددة. وفي هذا السياق تمثلت

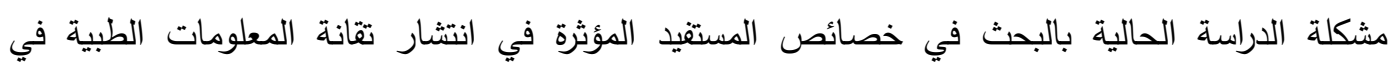
المستثفيات الخاصة في دهوك، وتم تمثيل مشكلة الدراسة بالتساؤلات الآتية:

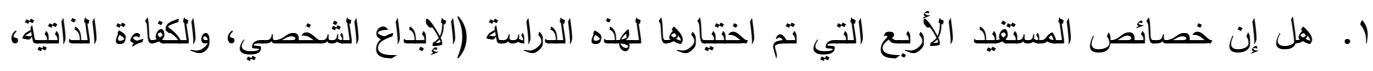

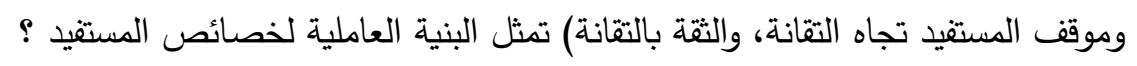
r. هل تؤثر خصائص المستفيد (على مستوى كل عامل وعلى المستوى الكلي) في انتثار تقانة المعلومات

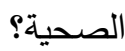

ثانيا: أهمية الدراسة

تأخذ الدراسة أهميتها من أنها تمثل محاولة لبناء واختبار أنموذج يتضمن خصائص للمستفيد محتملة

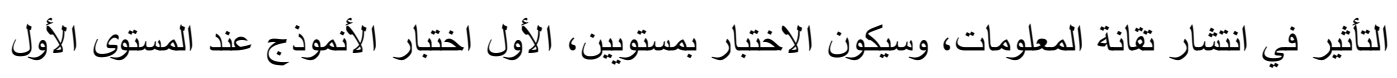
First-Order Factor

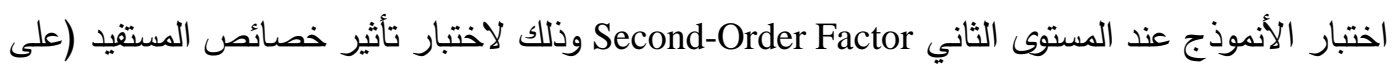
المستوى الكلي) في انتثار تقانة المعلومات الصحية. أما الأهمية الميدانية فهي تتأتى من خلال اختيار

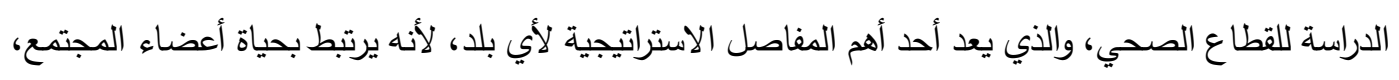

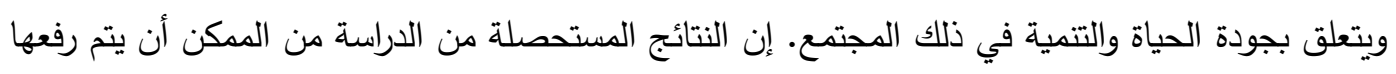
إلى إدارات المستثفيات بها، وذلك لغرض جذب انتباه هذه الإدارات إلى أهم ما تم التوصل إليه بشأن

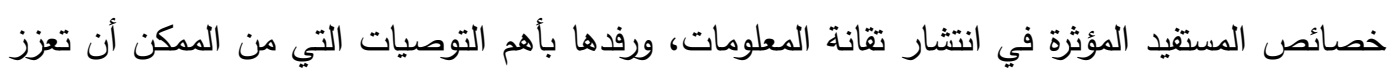
حالة انتشار التقانة. 


$$
\text { ثالثا: أهداف الدراسة }
$$

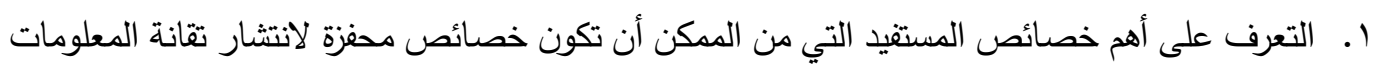

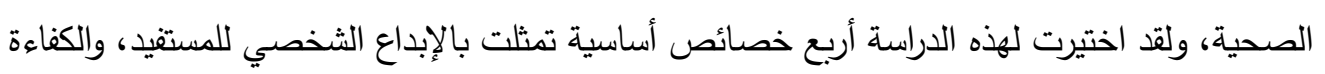
الذاتية، ومواقف المستقيد تجاه التقانة، والثقة بتقانة المعلومات. r. اختبار أنموذج الدراسة الذي يوضح تأثير خصائص المستقيد في انتشار تقانة المعلومات، وسيكون بانة الاختبار بناءً على استجابات عينة من الكادر الصحي العامل في المستثفيات الأهلية في محافظة دهوك.

المحور الثاني: بناء أنموذج الدراسة وفرضياتها تعد نظرية انتشار الإبداع واحدة من أهم النظريات والاكثر قبولا في مجال دراسة سلوكيات الماتوات المستفيدين

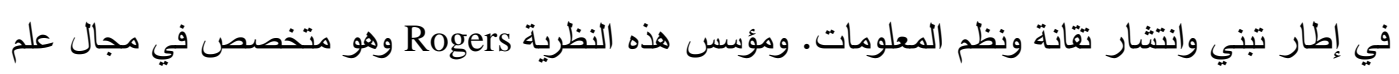
الاجتماع، وكان اهتمامه منصبا آنذالك على تحديث المجتمع الريفي الامريكي وجعله مواكبا للتغيرات

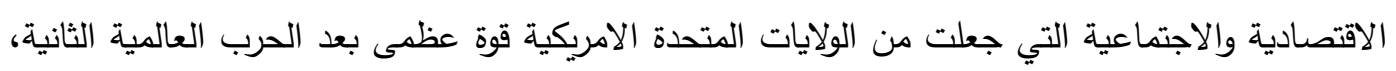

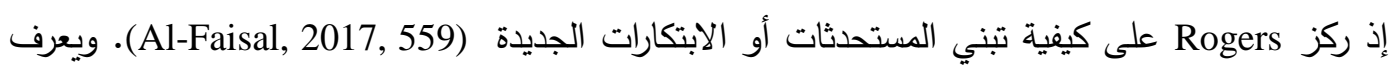

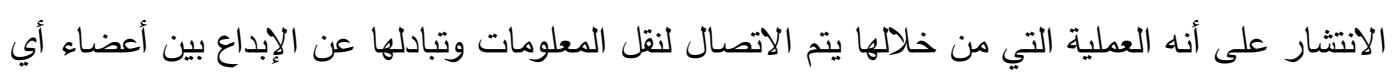
نظام اجتماعي عبر قنوات محددة في وقت محدد، وهو يمثل نوعاً خاصاً من الاتصال، ويكون محور اهتمام

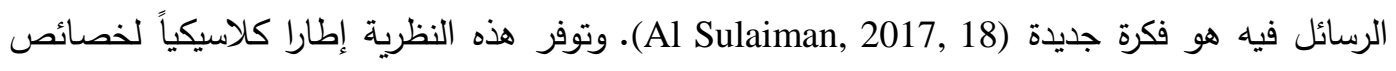

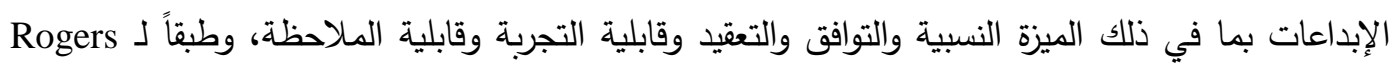

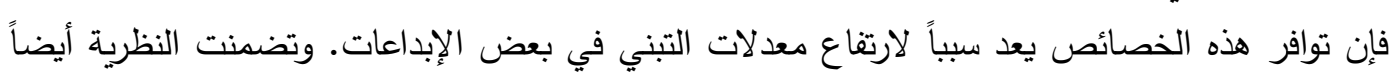

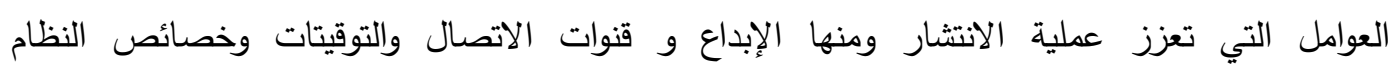
الاجتماعي(Zhang, 2018,1).

وفيما يتعلق بأنموذج الدراسة، ينظر إلى الأنموذج أيضاً على أنه مخطط يوضح العلاقة بين العوامل

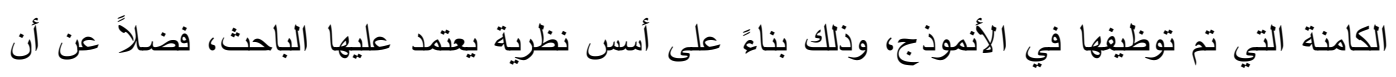

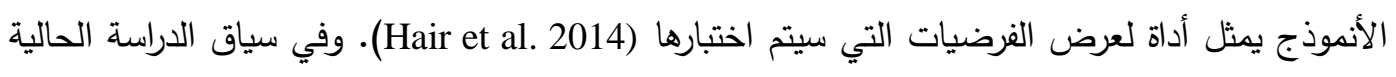
فإن خصائص المستقيد التي تضمنها أنموذج الدراسة والتي تؤثر في انتشار تقانة المعلومات الصحية تمثلت بالآتي:

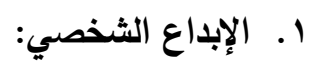

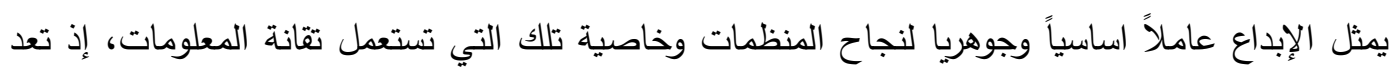
المعرفة مفتاح الحصول على الموارد كافة. والإبداع الثخصي في مجال تقانة المعلومات لله تأثيرات في تلفي

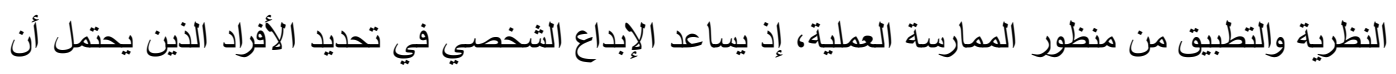


يتبنوا تقانة المعلومات، ويمكن لهؤلاء الأفراد بعد ذلك العمل كوكلاء تغيير وقادة رأي لتسهيل نشر التقانة الجديدة (Agarwal \& Prasad, 1998, 205). لقد شخصت أدبيات نظم المعلومات مشكلة أساسية تتمثل في لقاني أن بعض الأفراد يتبنون تقانة المعلومات الجديدة بسهولة، في حين إن الآخرين لا يقبلون هذه التقانات. ولقد

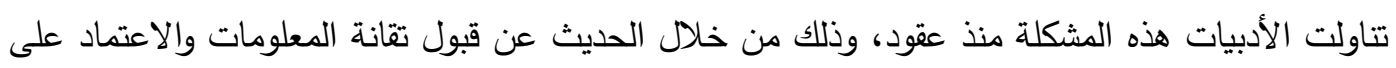

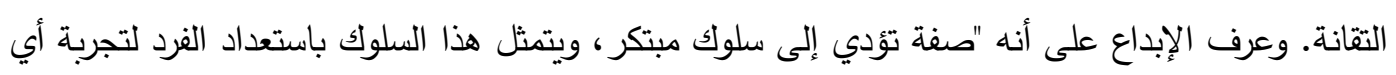

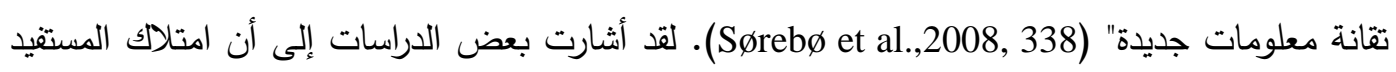

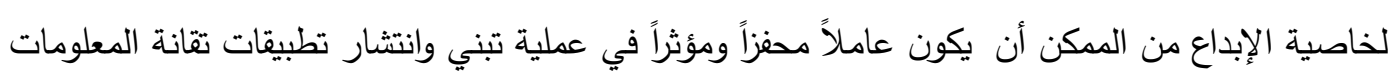
من قبل المستقيدين (Quaddus et al. 2005). ولقد أثبتت دراسة (2013) .Jackson et al أن للإبداع الثخصي فئسي

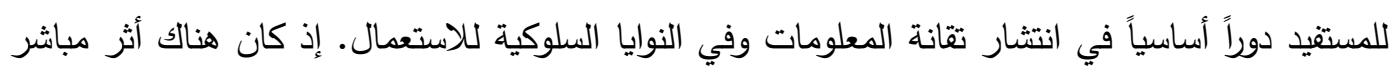
للإبداع الشخصي في انتشار التقانة وأثر غير مباشر للإبداع الثخصي لتعزيز النوايا السلوكية من خلال

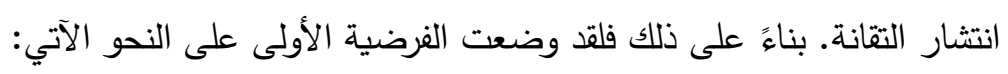

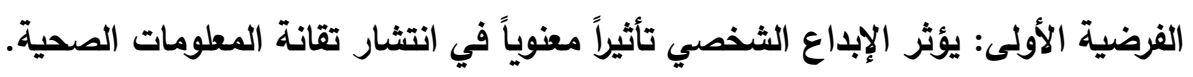

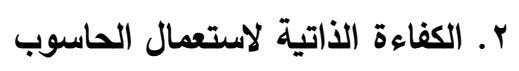

تعد الكفاءة الذاتية ( Self-efficacy) من المتغيرات المهمة التي توجه سلوك الفرد، وتسهم في تحقيق

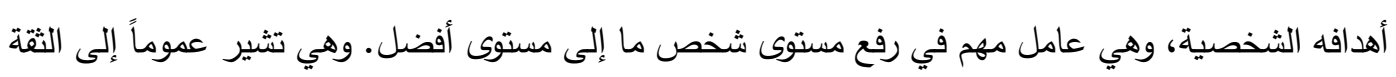

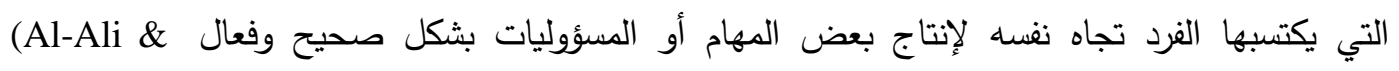
Mohammmed, 2016, 483) لقد انبثق مفهوم الكفاءة الذاتية من خلال ما يعرف بنظرية المعرفة الاجتماعية، وكان الهدف الأساسي لهذه النظرية هو التقسير الإنساني، ولقد توصلت الدراسات في هذا المجال

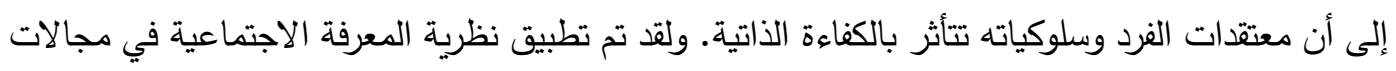
عديدة ومنها مجال تقانة المعلومات. إذ أشار (1995) Compeau \& Higgins إلى أن الكفاءة الذاتية تؤثر

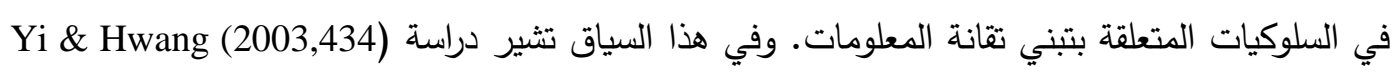

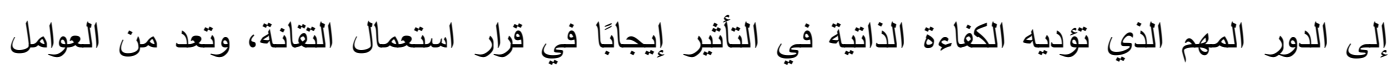

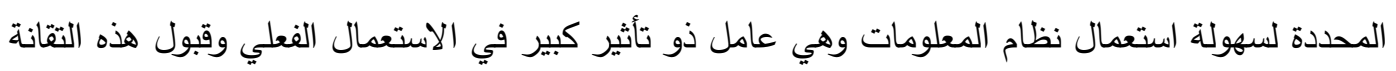

وانتشارها. بناءً على ذلك فلقد تم بناء الفرضية الثانية الآتية:

الفرضية الثانية: تؤثر الكفاءة الذاتية لاستعمال الحاسوب تأثيراً معنوياً في انتثار تقانة المعلومات الصحية r. موقف المستفيد تجاه التقانة

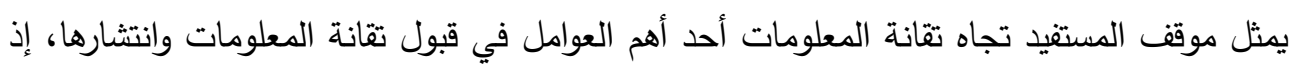
إن معظم النظريات التي تتاولت موضوع قبول تقانة المعلومات وانتشارها قد اعتمدت موقف المستقيد تجاه (TAM1, TAM2, التقانة كعامل أساسي في هذه النظريات ومنها أنموذج قبول التقانة باصدارته الثثلاثنة

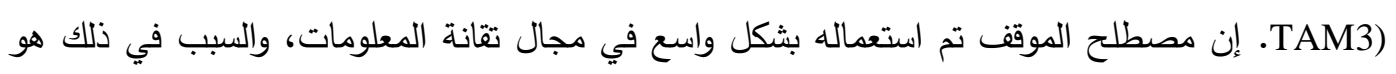


لدراسة السلوك الإنساني في هذا المجال. إن الموقف من تقانة المعلومات يتعلق بوجود رأي إيجابي بشأن

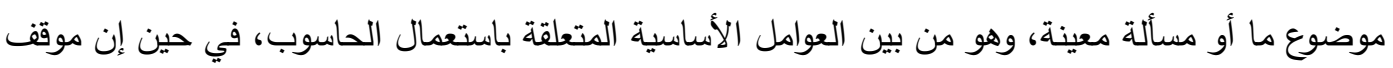

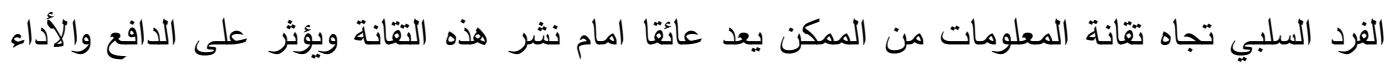

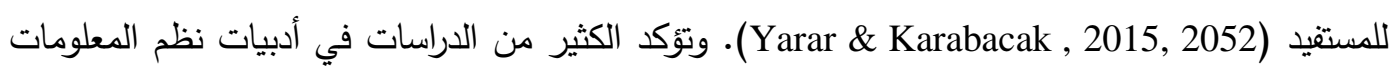

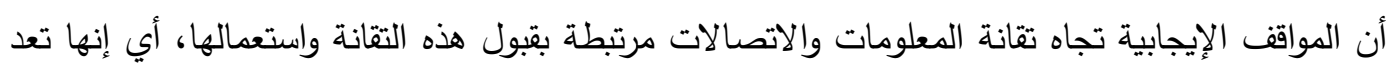

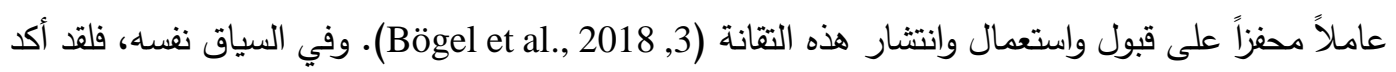

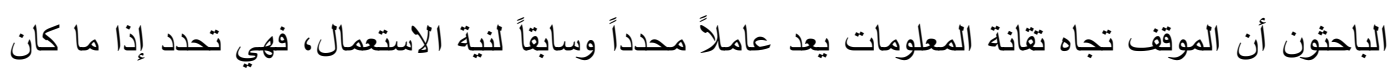

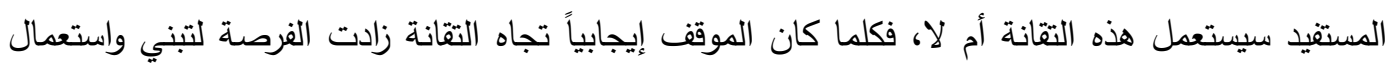

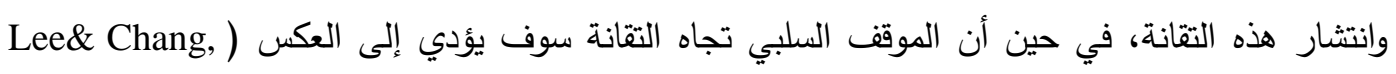

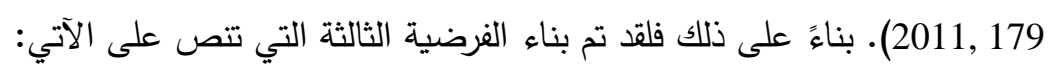

الفرضية الثالثة: يؤثر موقف المستفيد تجاه التقانة تأثيراً معنوياً في انتثار تقانة المعلومات التئ الصئ الصحية ع. الثقة بتقانة المعلومات

إن ثقة المستفيد بتقانة المعلومات مبنية بالطريقة نفسها التي تبنى بالأفراد، إذ إن أداء تقانة المعلومات

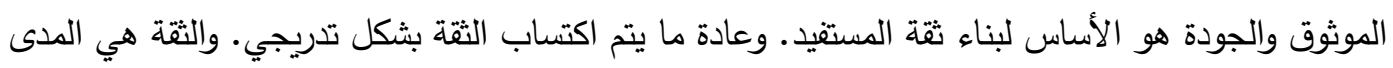
الذي يكون فيه طرف ما على استعداد للاعتماد على شيء أو شخص ما في موقف معين مع شعور بالأمان

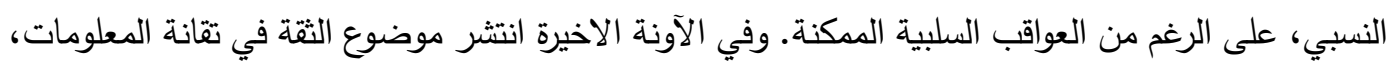

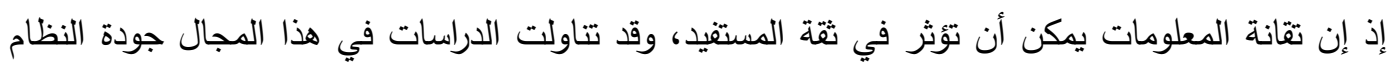
بصفتها عوامل لها دور في إضفاء التقة بتقانة المعلومات. إذ ترتبط سمات جودة النظام بمفهوم الثقة والأبحاث الحديثة تثير إلى أن الجوانب الفنية لعناصر تقنية المعلومات تئثر في رغبة المستعملين في منح الثقة. وقداء

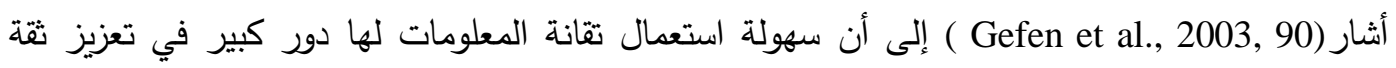

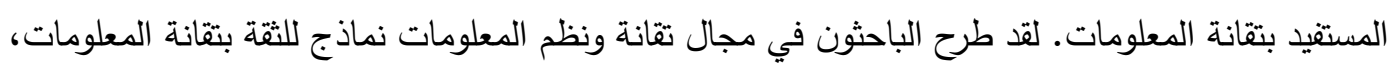

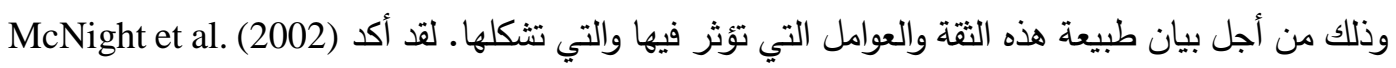
أن الثقة تعد عاملاً أساسياً، لأنها تساعد المستفيدين في تجاوز توقعات حالة عدم التأكد والمخاطر من استعمال

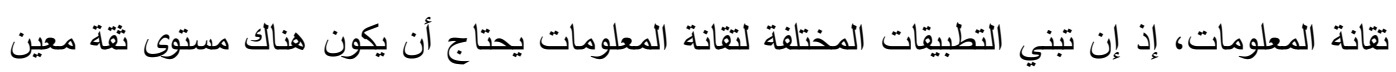

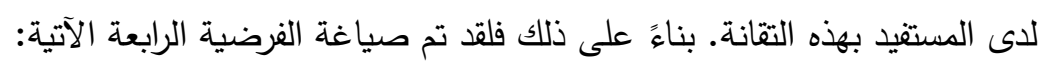


خصائص المستفيد ودورها في انتشار تقانة المعلومات............ طه والسبعاوي

الفرضية الرابعة: تؤثر ثقة المستفيد تأثيراً معنوياً في انتشار تقانة المعلومات الصحية

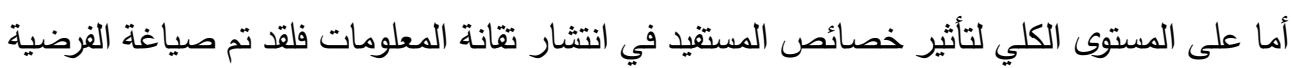

الفرضية الخامسة: تؤثر خصائص المستفيد تأثيراً معنوياً في انتشار تقانة المعلومات الصحية.

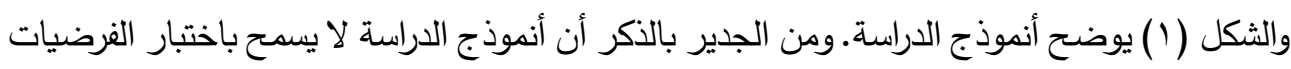

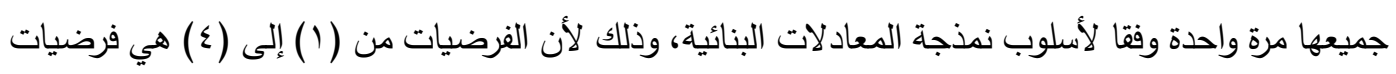

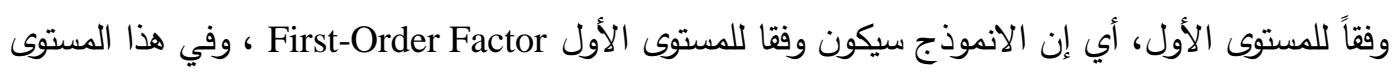

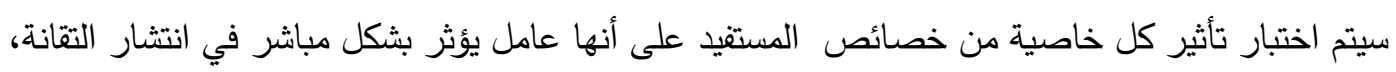

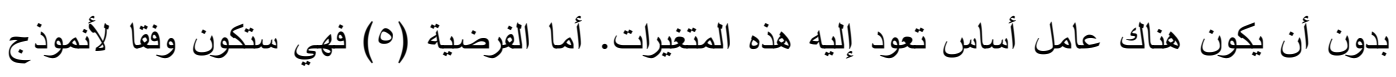
المستوى الثاني Second-Order Factor. أي إنه سيتم أخذ خصائص المستقيد الأربع، ولكنها ستكون أبعاداً فرعية لعامل كامن واحد.

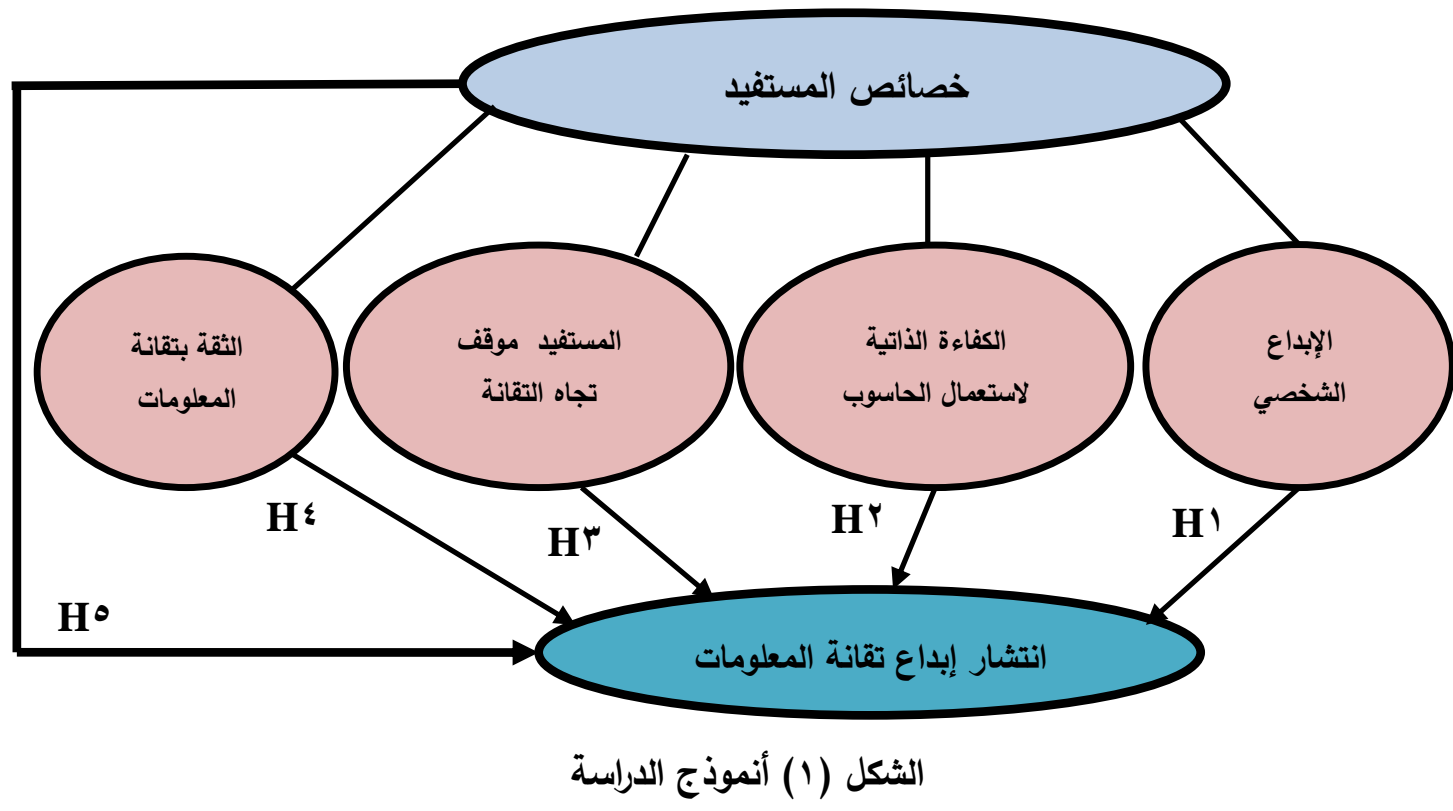

المحور الثالث: منهجية الدراسة

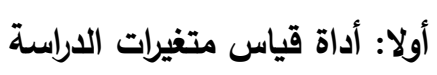

تم اعتماد استمارة الاستبانة' كأداة لقياس متغيرات الدراسة الحالية، علما أن الاستمارة تم إعدادها

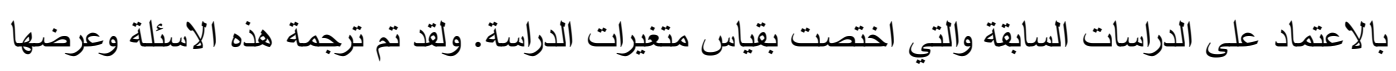

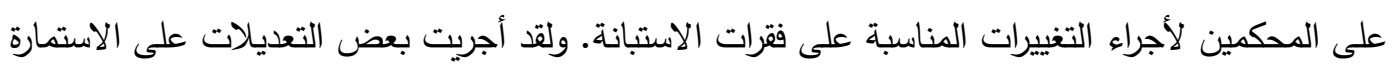

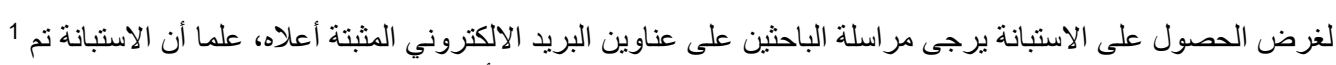
رفعها، وذلك لتقليص عدد أوراق البحث لنكون مطابقة لتعليمات المجلة. 
وفقا لآراء الخبراء والتي تم مراجعتها بثكل دقيق وأخذ الملائم منها بنظر الاعتبار • ولقد تم اعتماد مقياس ليكرت الخماسي (اتفق بثدة إلى لا اتفق بثدة) لقياس آراء المبحوثين. ثانياً: عينة الاراسة تمثلت عينة الدراسة بالكادر الطبي في جميع المستشفيات الأهلية في دهوك (ست مستثفيات هي

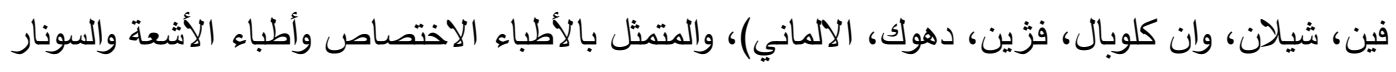

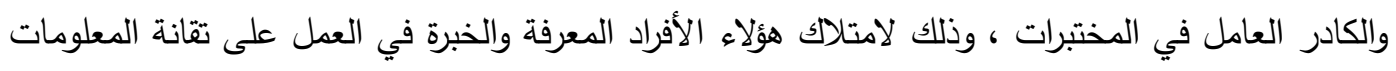

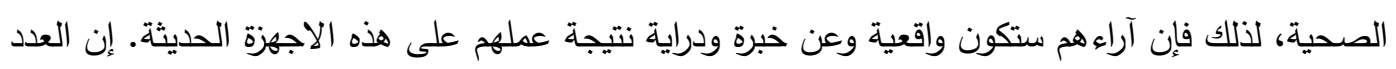

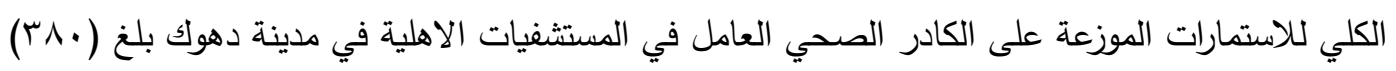

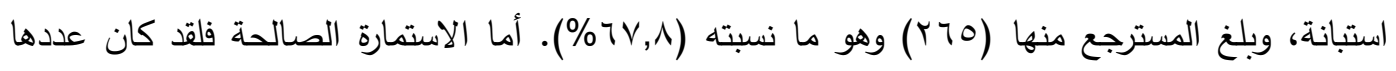

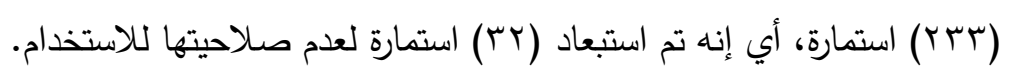

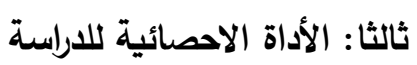

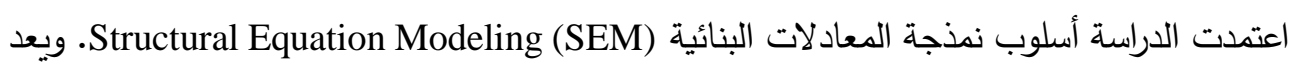
هذا الأسلوب من الأساليب الحديثة في مجال اختبار النماذج. وفيما يتعلق بمؤشرات حسن مطابقة الأنموذج،

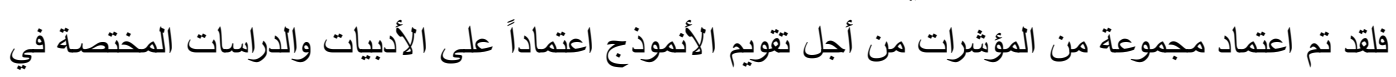

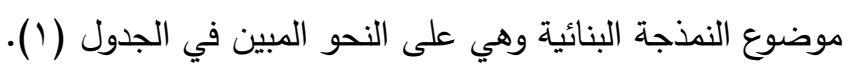

\begin{tabular}{|c|c|c|c|}
\hline التوضيح & حدود القبول & مؤشر القبول & $ت$ \\
\hline التطابق الكبرى من • 9, · تعكس & 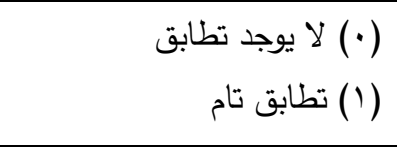 & $\begin{array}{r}\text { GFI } \\
\text { Goodness of Fit Index } \\
\text { مؤشر حسن المطابقة }\end{array}$ & 1 \\
\hline إلى تطابق جيد للأنموذج من الكبرى · تثير & 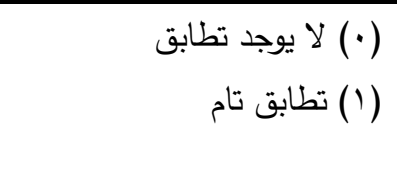 & $\begin{array}{r}\text { AGFI } \\
\text { Adjusted Goodness of Fit } \\
\text { Index } \\
\text { مؤشر حسن المطابقة المصحح }\end{array}$ & 2 \\
\hline يشير إلى تقارب $\Sigma$ إلى S & 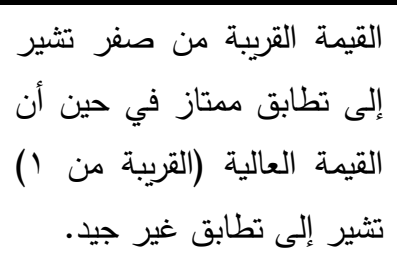 & $\begin{array}{r}\text { RMR } \\
\text { Root Mean Square Residual } \\
\text { جذر متوسط مربعات البواقي }\end{array}$ & 3 \\
\hline تطابق الأنموذج 1 الأدنى 0.06 تثير إلى & $\leq 0.06$ & $\begin{array}{r}\text { RMSEA } \\
\text { Root Mean Square Error of } \\
\text { Approximation } \\
\text { مؤشر جذر متوسط مربع الخطأ } \\
\text { التقريبي }\end{array}$ & 5 \\
\hline
\end{tabular}




\begin{tabular}{|c|c|c|c|}
\hline التوضيح & حدود القبول & مؤشر القبول & ت \\
\hline القيم الكبرى من • 9, • أو 90 , & 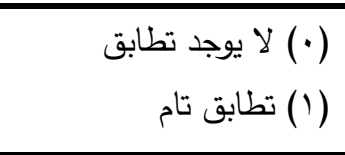 & $\begin{array}{r}\text { TLI } \\
\text { Tucker-Lewis Index } \\
\text { مؤشر توكر لويس }\end{array}$ & $\overline{6}$ \\
\hline 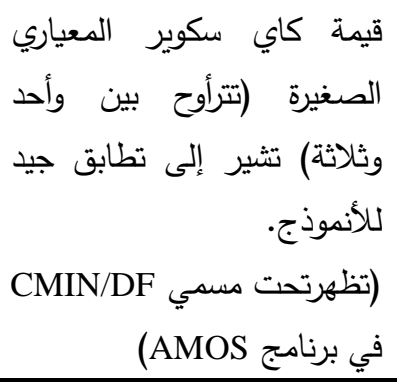 & اكبر من (1) واقل من (r) & كاي سكوير المعياري(x2/df) & $v$ \\
\hline القى تطابق جيد للأنموذج من 90 ، تشير & 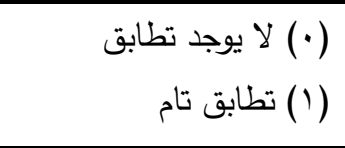 & $\begin{array}{r}\text { CFI } \\
\text { Comparative Fit Index } \\
\text { مؤشر المطابقة المقارن }\end{array}$ & $\wedge$ \\
\hline 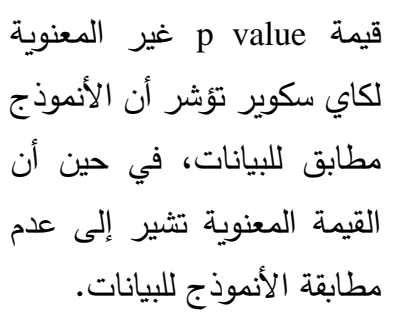 & $\mathrm{p}$ value $>0.05$ & $\mathrm{p}$ value & 9 \\
\hline
\end{tabular}

Source: (Alsabawy, 2019, 24)

فضلا عن استخدام اختبارات خاصة بالصدق والثبات مثل اختبار الصدق التقاربي وصدق بناء

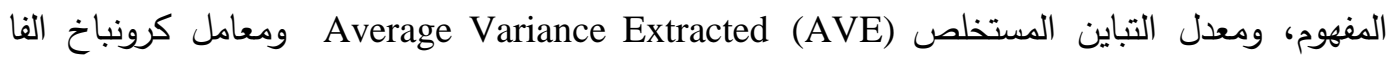

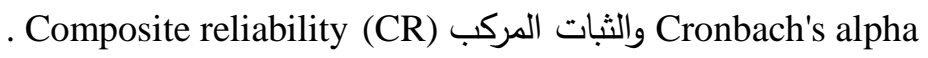

$$
\text { أولاً: اختبار أنموذج الرابع: الإطار العملي للاراسة }
$$

تمثلت الخطوة الأولى في اختبار أنموذج الدراسة باختبار أنموذج القياس، وذلك للتأكد من صلاحية الأنموذج ومصداقيته في عملية قياس العوامل الكامنة وتحديد نقاط الضعف في الأنموذج ومؤشرات القياس لتاني

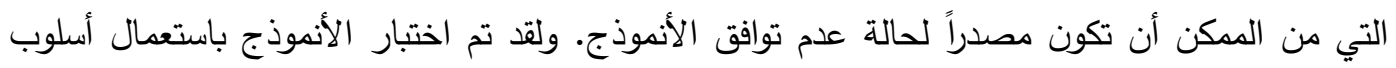

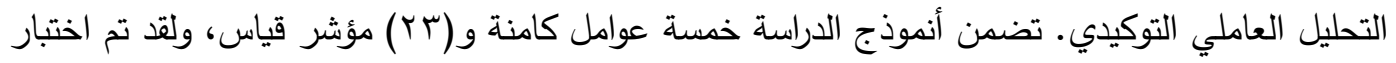

الأنموذج في المرحلة الأولى، وكانت مؤشرات حسن مطابقة الأنموذج للمرحلة الأولى على النحو الآتي: GFI, 0.825; AGFI, 0.780; RMR, 0.095; RMSEA, 0.082; TLI, 0.883; ( $\left.\chi^{2} / \mathrm{df}\right), 2.554$;

CFI, 0.898; P. 000. 
ولقد بينت نتائج مراجعة مؤشرات تعديل الأنموذج أن مؤشر القياس (X16) قد ارتبط بشكل عالٍ مع

مؤشرات قياس أخرى مثلاً مع مؤشر القياس (X18) وبقيمة (88.489) وهي قيمة ارتباط تعد عالية جداً.

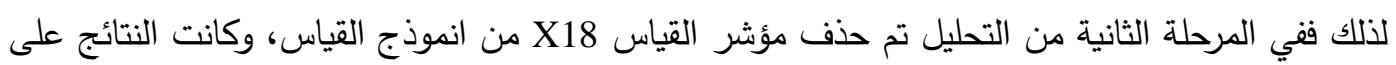
النحو الآتي:

GFI, 0.868 ; AGFI, 0.833 ; RMR, 0.069 ; RMSEA, 0,066; TLI, 0.928 ( $\chi^{2} /$ df), 1,997;

CFI, 0.938 ; P. 000.

لقد بينت نتائج مراجعة مؤشرات تعديل الأنموذج أن مؤشر القياس (X5)" قد ارتبط بشكل عالٍ مع

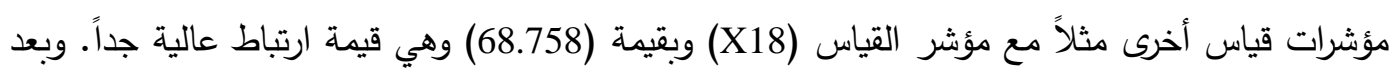
حذف مؤشر القياس X5 كانت نتائج حسن المطابقة على النحو الآتي: GFI, 0.893 ; AGFI, 0.861 ; RMR, 0.053 ; RMSEA, 0.053; TLI, .957; ( $\left.\chi^{2} / \mathrm{df}\right)$, 1.646;

CFI, .963 ; P. 000

ولقد تبين من خلال تدقيق مؤشرات تعديل الأنموذج أن مؤشر القياس (X13)" قد ارتبط بشكل عالٍ

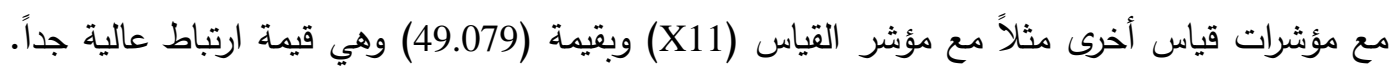
استناداً إلى هذه النتائج تقرر أن يتم حذف مؤشر القياس (X13)، وكانت نتائج مؤن حسن المطابقة على النحو

GFI, 0.916 ; AGFI, 0.889 ; RMR,0 .050; RMSEA, 0.040; TLI,0.977 ; $\left(\chi^{2} / \mathrm{df}\right), 1.368$;

$$
\text { الآتي: }
$$

CFI, $0.981 ;$ P. 000

وفي المرحلة الخامسة تبين أن مؤشر القياس (X18) يعاني من مشكلة في عملية القياس وبخاصة

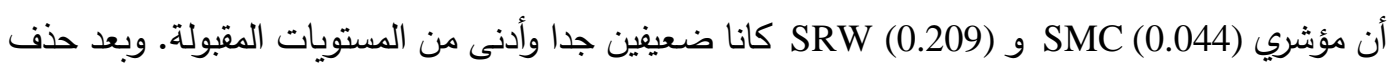
هذا المؤشر كانت نتائج حسن المطابقة على النحو المبين في أدناه:

GFI, 0.922 ; AGFI, 0.896 ; RMR, .044; RMSEA .040; TLI, 0.979; ( $\left.\chi^{2} / \mathrm{df}\right), 1.366$;

CFI, $0.983 ;$ P. 000

يتبين من خلال النتائج المذكورة آنفاً أن الأنموذج قد حقق المطابقة، إذ إن جميع مؤشرات القياس

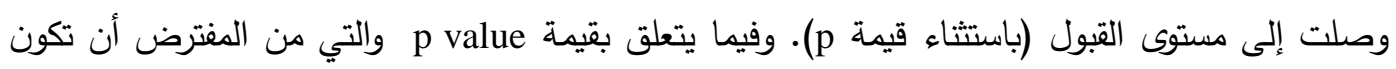

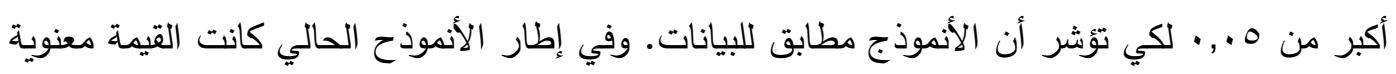

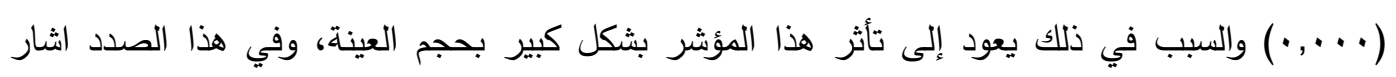
(Schumacker \& Lomax(2010) إلى أن مؤشر كاي سكوير يتأثر بشكل كبير بحجم العينة، إذ إنه كلما

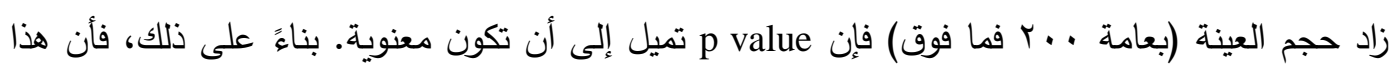

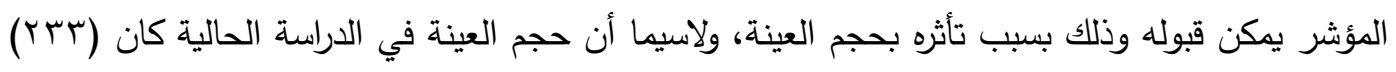
مفردة. ويلاحظ من خلال النظر في الجدول (r) أن جميع مؤشرات القياس كانت معنوية في تمثيل العامل الكامن الذي وظفت لقياسه. ويبين الثكل (r) أنموذج القياس النهائي للدراسة. لقد تم توظيف العديد من مؤشرات الصدق والثبات، وذلك من أجل التأكد من مؤشرات القياس والعوامل الكامنة في عملية القياس. وفيما يتعلق بالصدق التقاربي فهو يشير إلى العلاقة بين مؤشرات القياس (المتغيرات 
المشاهدة) والعوامل الكامنة، أي إن مؤشرات القياس تعمل بالطريقة نفسها لتمثيل عامل كامن معين Brown) \& Moore, 2012)

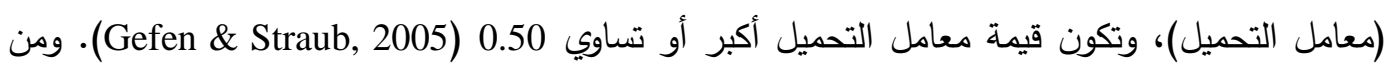
خلال النظر في الجدول (Y) يلاحظ أن قيم معامل التحميل (SRW) كانت عالية نسبيا، إذ كانت القيم تتراوح

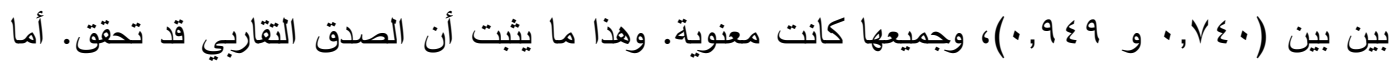
الصدق البنائي فيعرف على أنه المدى الذي تمثل فيه مجموعة من مؤشرات القياس وبشكل حقيقي المفهوم

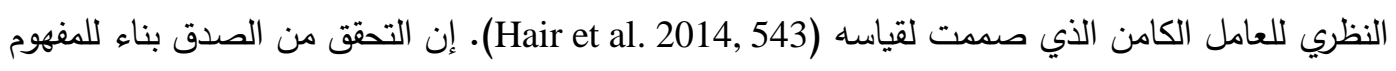
يتم من خلال مؤشرات حسن مطابقة الانموذج، إذ إن وصول مؤشرات حسن المطابقة إلى المستوى المقبول

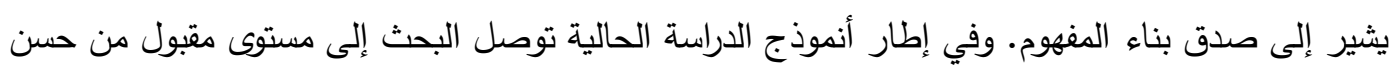

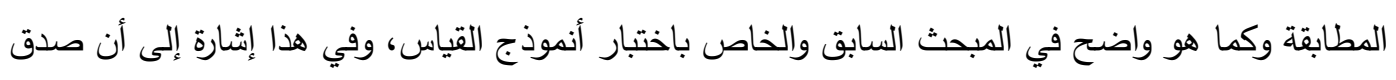
بناء المفهوم قد تحقق. وفيما يتعلق باختبارات الثبات، فقد تم الاعتماد على اربعة اختبارات أساسية، وأولها كان ثبات الفقرة.

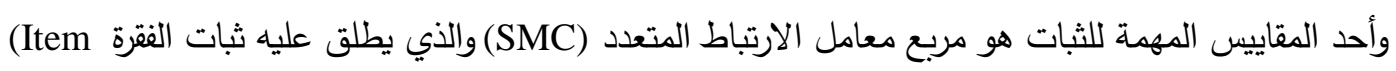

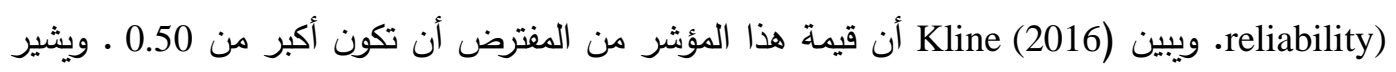

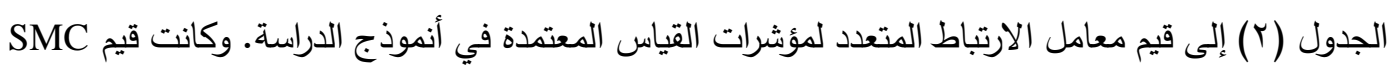

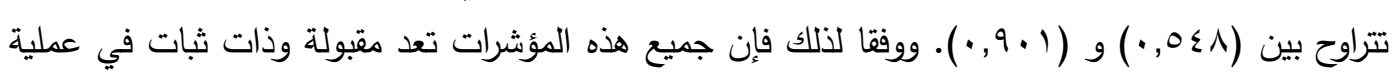

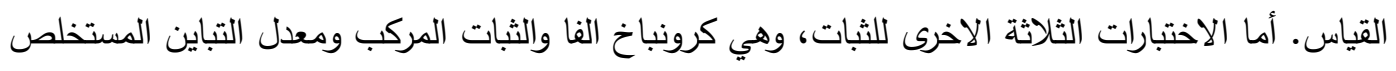

فكانت نتائج هذه الاختبارات على النحو المبين في الجدول (r). 


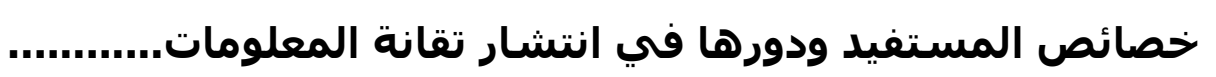
طa والسبعاوي

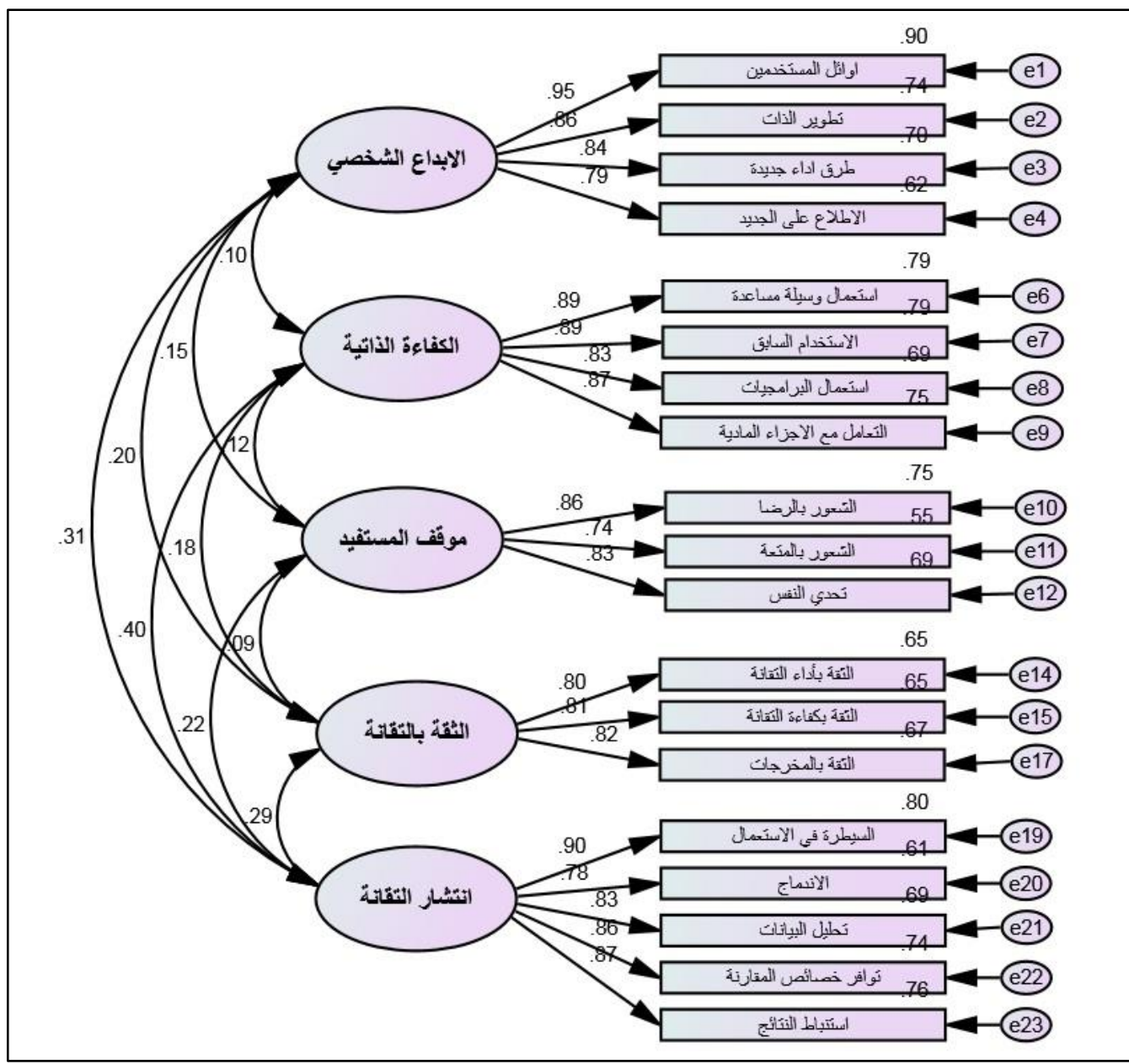

الشكل (r): انموذج القياس النهائي للدراسة

يتبين من خلال النظر في الجدول (r) ان العوامل الكامنة التي تثكل منها انموذج الدراسة قد حققت

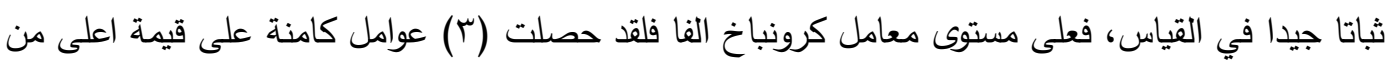

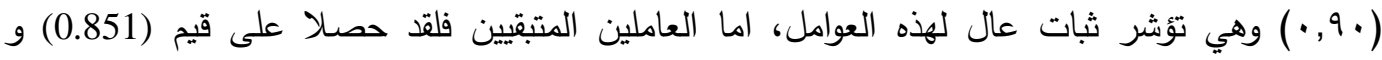

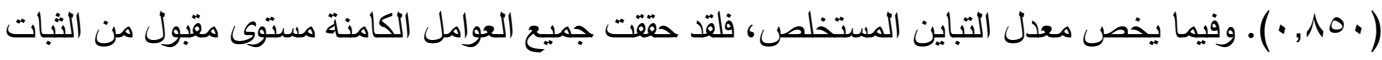
فيما يخص هذا المؤشر (اكثر من • 0, •). وكذلك الحال بالنسبة لمعامل الثبات المركب، اذ ان جميع العوامل مئل الكامنة قد حققت قيمة ثبات مركب اكبر من • V, •. 


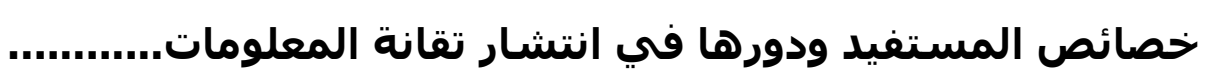
طه والسبعاوي

الجدول (ץ): نتائج تحليل الاندار للمرحلة الاخيرة من أنموذج القياس وبعض مؤشرات الصدق والثبات

\begin{tabular}{|c|c|c|c|c|c|c|c|c|c|c|}
\hline مُوَّبُس & & الكامن & Estimate & $\begin{array}{l}\text { Critica } \\
\text { I Ratio }\end{array}$ & $\mathbf{P}$ & SRW $^{2}$ & $\mathrm{SMC}^{3}$ & $\mathrm{AVE}^{4}$ & Alpha & CR \\
\hline $\mathrm{X} 1$ & $<$ & الثخفيدي & 1.000 & - & - & .949 & .901 & \multirow{4}{*}{.741} & \multirow{4}{*}{.918} & \multirow{4}{*}{.856} \\
\hline $\mathrm{X} 2$ & $<$ & $\begin{array}{l}\text { الثخصبدي } \\
\text { الأبداع }\end{array}$ & .852 & 20.188 & $* * *$ & .859 & .737 & & & \\
\hline $\mathrm{X} 3$ & $<$ & الثخصبي الابداع & .855 & 19.157 & $* * *$ & .839 & .705 & & & \\
\hline $\mathrm{X} 4$ & $<$ & الثخصبي & .810 & 16.779 & $* * *$ & .789 & .623 & & & \\
\hline $\mathrm{X} 6$ & $<$ & الكنا هئة الذانتِِة & 1.000 & - & - & .889 & .791 & \multirow{4}{*}{.754} & \multirow{4}{*}{.924} & \multirow{4}{*}{.902} \\
\hline $\mathrm{X} 7$ & $<-$ & الكنا هئ الذاتبِة & .983 & 19.246 & $* * *$ & .890 & .791 & & & \\
\hline $\mathrm{X} 8$ & $<$ & الكفا هئ الذانية & .887 & 16.776 & $* * *$ & .828 & .685 & & & \\
\hline $\mathrm{X} 9$ & $<$ & الكفاهـة الذائِية & .945 & 18.926 & $* * *$ & .886 & .750 & & & \\
\hline $\mathrm{X} 10$ & $<$ & موئف المعنقِّب & 1.000 & - & - & .865 & .748 & \multirow{3}{*}{.662} & \multirow{3}{*}{.850} & \multirow{3}{*}{.800} \\
\hline $\mathrm{X} 11$ & $<$ & موقَف العمنقِيد & .742 & 11.809 & $* * *$ & .740 & .548 & & & \\
\hline $\mathrm{X} 12$ & $<$ & موتُف للعمنَّبد & .895 & 19.246 & $* * *$ & .831 & .691 & & & \\
\hline $\mathrm{X} 14$ & $<$ & الثيقة بالثقانة & 1.000 & - & - & .805 & .648 & \multirow{3}{*}{.656} & \multirow{3}{*}{.851} & \multirow{3}{*}{.790} \\
\hline $\mathrm{X} 15$ & $<$ & الثقة بالثقانة & 1.012 & 12.076 & $* * *$ & .806 & .650 & & & \\
\hline $\mathrm{X} 17$ & $<$ & الثقة بالثبانة & 1.048 & 12.172 & $* * *$ & .818 & .670 & & & \\
\hline $\mathrm{X} 19$ & $<$ & 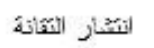 & 1.000 & - & - & .896 & .802 & \multirow{5}{*}{.720} & \multirow{5}{*}{.927} & \multirow{5}{*}{.907} \\
\hline $\mathrm{X} 20$ & $<$ & لنشار لانثانة & .882 & 15.450 & $* * *$ & .783 & .614 & & & \\
\hline $\mathrm{X} 21$ & $<$ & انبيار لنبانة & .919 & 17.225 & $* * *$ & .830 & .690 & & & \\
\hline $\mathrm{X} 22$ & $<$ & انبتار النثانة & .971 & 18.421 & $* * *$ & .859 & .738 & & & \\
\hline $\mathrm{X} 23$ & $<$ & الثتار لانعانة & 1.001 & 18.926 & $* * *$ & .870 & .757 & & & \\
\hline
\end{tabular}

المصدر: من اعداد الباحثين بالاستتاد الى مخرجات برنامج AMOS

ثانيا: اختبار فرضيات الدراسة (الانموذج البنائي)

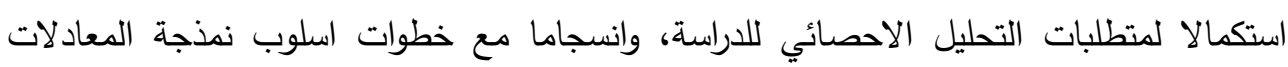
البنائية، فلقد اختصت هذا الدراسة بأختبار الانموذج البنائي للدراسة. وكما اشرنا في منهجية الدراسة حول

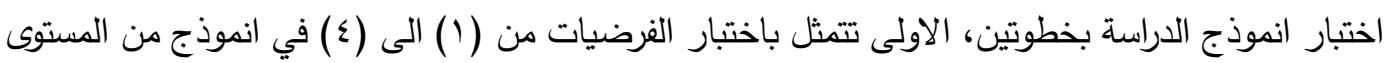

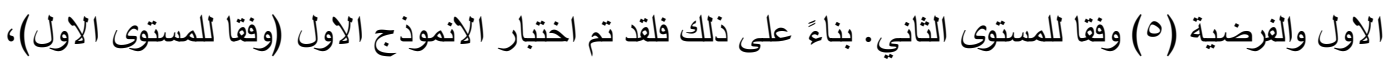
والثكل (r) والجدول (r) يوضحان نتائج اختبار الانموذج. 


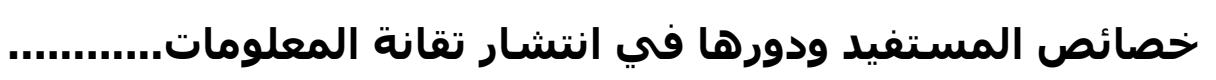
طه والسبعاوي

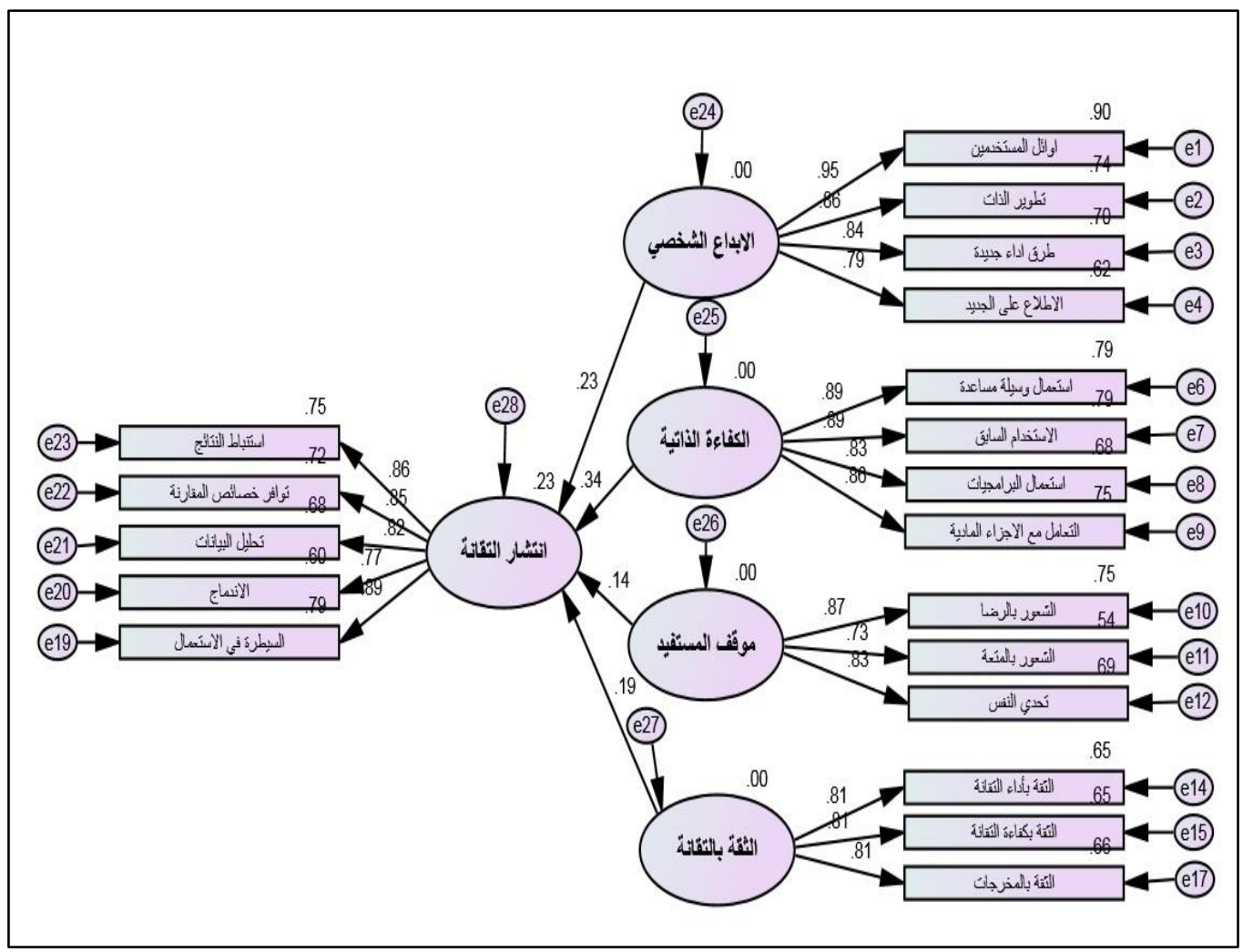

الثكل (ץ): نتائج اختبار تأثير خصائص المستفيد في انتثار التقانة (على مستوى كل خاصية)

الجدول (r): نتائج تحليل تأثير خصائص المستفيد في انتشار تقانة المعلومات (على مستوى كل خاصية)

\begin{tabular}{|c|c|c|c|c|c|c|c|c|}
\hline المتغير المعتمد & & المستفلة & Estimate & S.E. & C.R. & $\mathbf{P}$ & الفرضية & طأتبيعة \\
\hline انتشار تقانة المعلومات & $<--$ & الابداع الثخصي & .207 & .057 & 3.646 & $* * *$ & 1 & معنوي \\
\hline انتشار تقانة المعلومات & $<--$ & الكفاءة الذاتية & .372 & .071 & 5.255 & $* * *$ & 2 & معنوي \\
\hline انتشار تقانة المعلومات & $<---$ & موقف المستفيد & .147 & .070 & 2.091 & .037 & 3 & معنوي \\
\hline انتشار تقانة المعلومات & $<---$ & الثقة بالتقانة & .244 & .089 & 2.755 & .006 & 4 & معنوي \\
\hline
\end{tabular}

***Significant level is less than 0.001

تبين نتائج اختبار انموذج الدراسة ان خصائص المستقيد الاربعة والمتمثلة بالابداع الثخصي والكفاءة الذاتية وموقف المستفيد تجاه التقانة والثقة بالتقانة جميعها كانت ذات تأثير معنوي في انتشار تقانة المعلومات

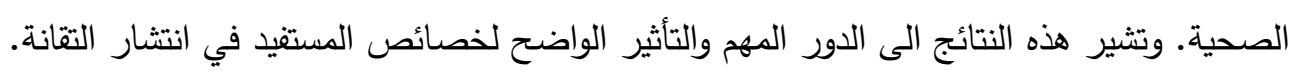

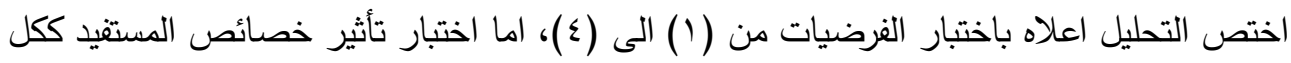
Second- على انتشار تقانة المعلومات (الفرضية الخامسة) فلقد تم اختباره وفقا لانموذج المستوى الثاني 


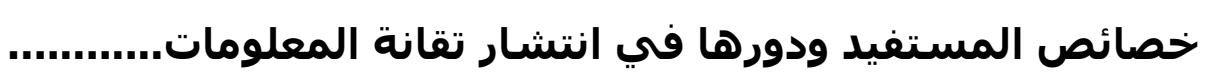
طa والسبعاوي

(§rder Factor

والجدول (乏).

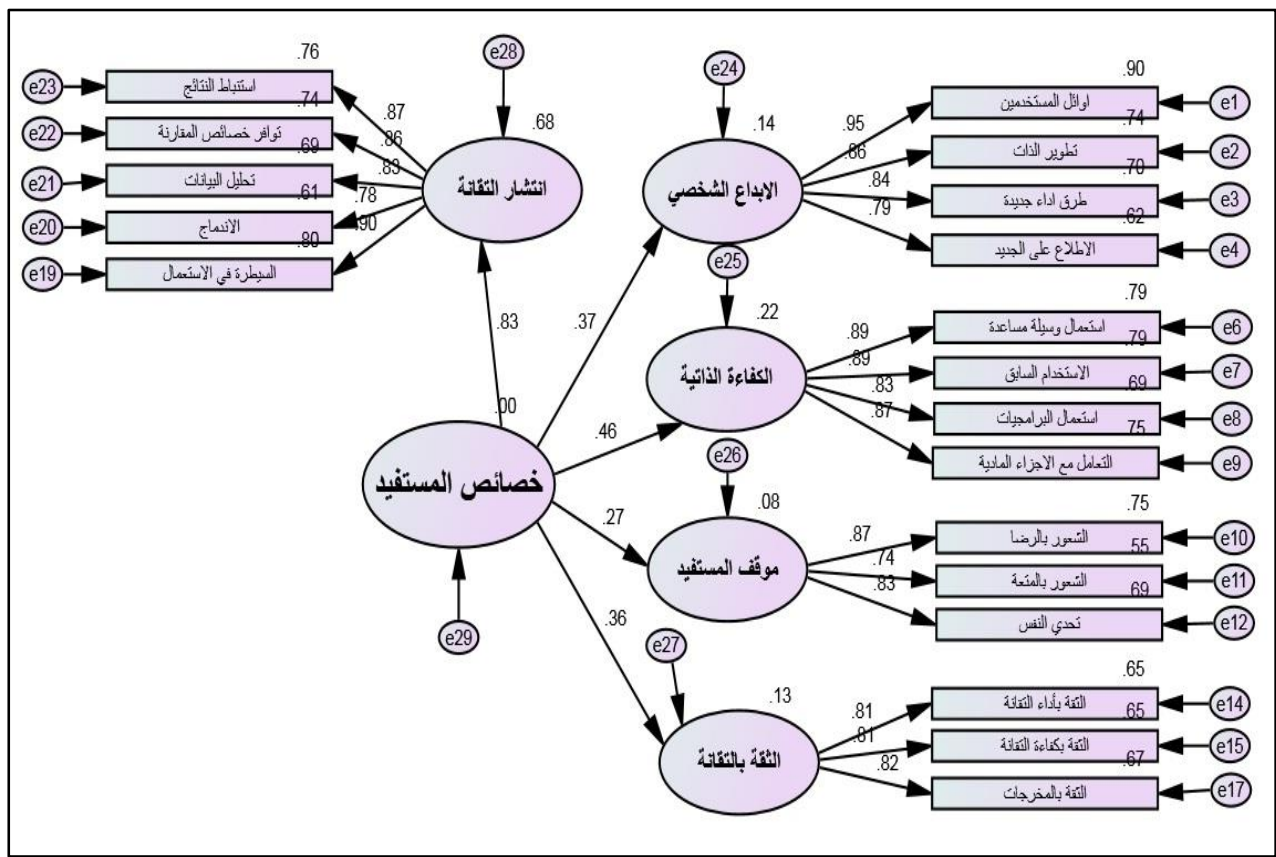

الشكل (؛ ): نتائج اختبار تأثير خصائص المستفيد في انتشار التقانة (على المستوى الكلي)

الجدول (؛ ) نتائج تحليل الانحدار لتأثير لخصائص المستفيد في انتشار تقانة المعلومات (المستوى الكلي)

\begin{tabular}{|c|c|c|c|c|c|c|c|c|}
\hline المتغير المعتمد & & المتغيرات المستقلة & Estimate & S.E. & C.R. & $\mathbf{P}$ & الفرضية & طبيعة \\
\hline الابداع الثخصي & $<--$ & خصائص المستفيد & 1.000 & & - & - & - & - \\
\hline الكفاءة الذاتية & $<---$ & خصائص المستفيد & 1.034 & .277 & 3.739 & $* * *$ & - & - \\
\hline موقف المستفيد & $<--$ & خصائص المستفيد & .621 & .229 & 2.716 & .007 & - & - \\
\hline الثقة بالتقانة & $<---$ & خصائص المستفيد & .664 & .207 & 3.215 & .001 & - & - \\
\hline انتشار التقانة & $<---$ & خصائص المستثيد & 2.060 & .590 & 3.489 & $* * *$ & 5 & معنوي \\
\hline
\end{tabular}

***Significant level is less than 0.001

يلاحظ من خلال النظر في الثكل (ع) والجدول (ع) ان خصائص المستفيد على المستوى الكلي

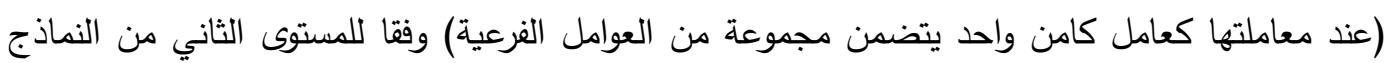

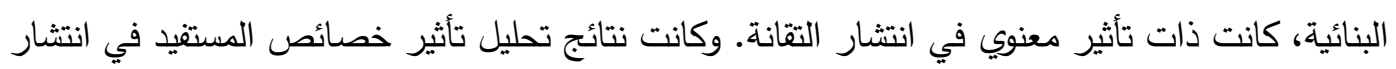

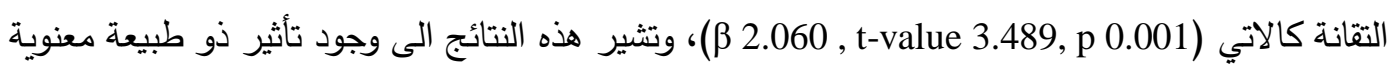

لخصائص المستفيد في انتشار تقانة المعلومات الصحية.

TANMIYAT AL-RAFIDAIN (P-ISSN: 1609-591X; E-ISSN: 2664-276X) تنمية الرافدين 
المحور الخامس: مناقشة نتائج الدراسة تم تخصيص هذا الجزء لمناقشة اختبار الانموذج البنائي عبر مناقشة الفرضيات وعلى النحو الاتي: الفرضية الأولى: يؤثر الإبداع الثخصي تأثيراً معنوياً في انتثار تقانة المعلومات الصحية لهنية

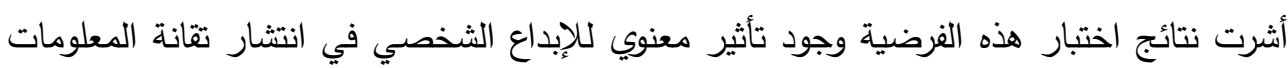

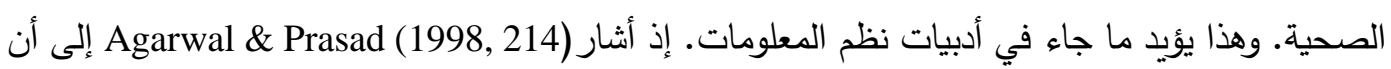
استعمال الإبداع الثخصي في مجال تقانة المعلومات يعد المحرك الأساسي لقرارات تبني وانتشار هذه التثقانة. وفي السياق نفسه، أكد Haug et al. (2018, 464) على ان الإبداع الثخصي هو المحدد الرئيس لانتشار

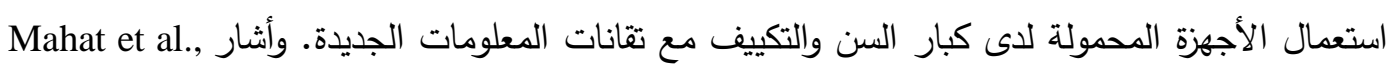
(2012, 288) وانتشارها إذ أكد أن الأفراد ذوي الإبداع الثخصي العالي هم أكثر قدرة على استكثاف التقانة الجديدة وتجربتها. وذكر ( Thakur et al. (2016, 6-7 أن الإبداع الثخصي مرتبط ارتباطًا وثيقًا بمستعملي الأدوات التقانية الحديثة، إذ إن هؤلاء الأفراد مفتونون بالخصائص الجديدة للمنتجات المتطورة مما يولد دافعاً جوهرياً لاستعمال

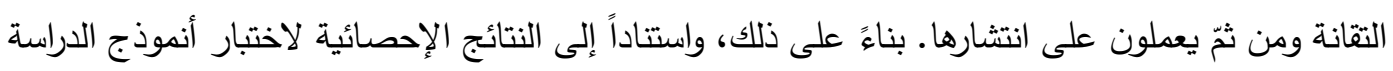
يتم قبول الفرضية الأولى. الفرضية الثانية: تؤثر الكفاءة الذاتية لاستعمال الحاسوب تأثيراً معنوياً في انتشار تقانة المعلومات الصحية بينّت نتائج اختبار هذه الفرضية وجود تأثير معنوي للكفاءة الذاتية في انتثار تقانة المعلومات الصحية.

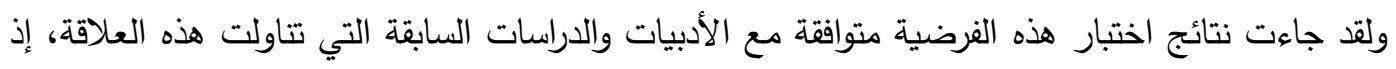

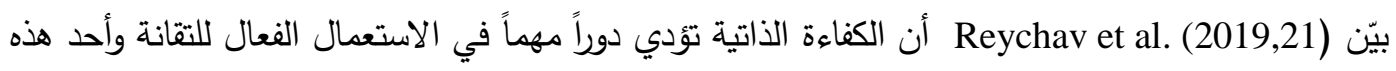
الاستعمالات تتمثل في تحسين موثوقية التقرير الذاتي للمرضى عند استعمال تطبيقات الأجهزة المحمولة

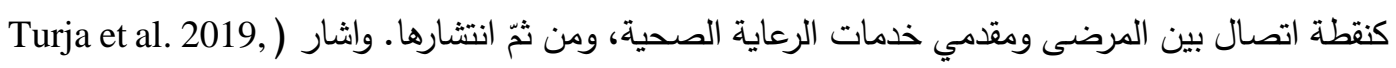

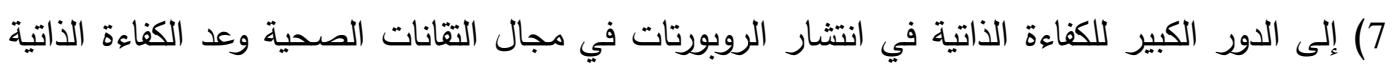

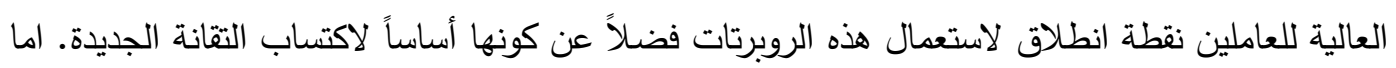
(6, Jacobs et al. (2019 ملقد توصل في دراسته على طلبة كلية الصيدلة بأن امتلاك الطلبة للكفاءة الذاتية في مجال تقانة المعلومات سوف يعزز استعدادهم لتبني ونثر تقانة المعلومات الصحية ودمج استعمال هذه دئه التقانة بسلاسة في الرعاية السريرية المستقبلية. بناءً على ما تم التوصل إليه من نتائج في اختبار الفرضية فئسية

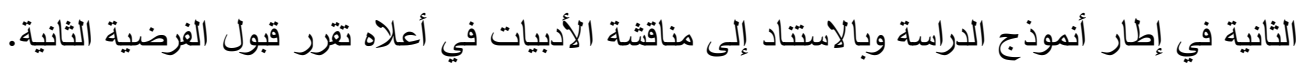

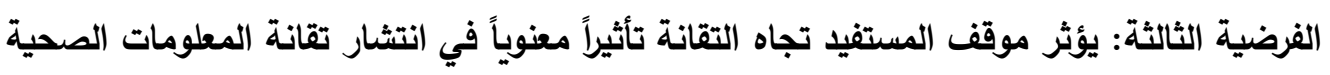

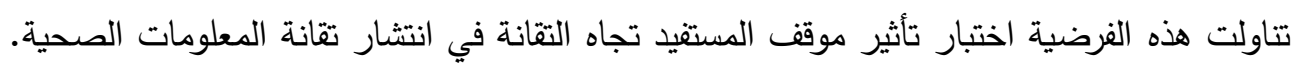

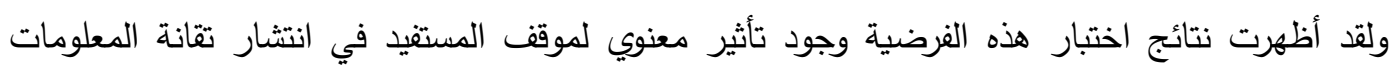

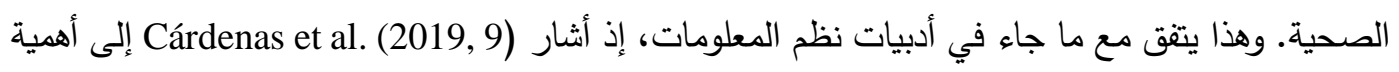


McLean et al. (2020,154-) المواقف تجاه التقانة في التتبؤ باستعمال وانتثار تقانة المعلومات. كما أكد 155 على المواقف الإيجابية تجاه تطبيقات الهاتف المحمول عبر التجارة الإلكترونية تؤدي إلى نتائج سلوكية إيجابية وزيادة الولاء للعلامات التجارية وتكرار الثراء وتكرار استعمال الهاتف المحمول في عمليات الثراء،

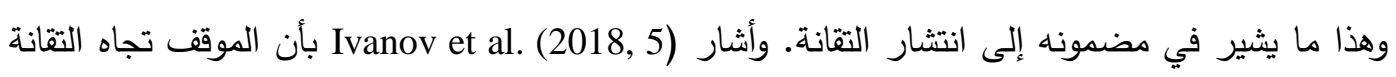

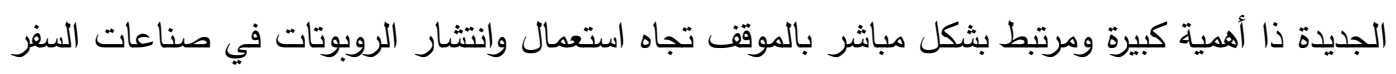

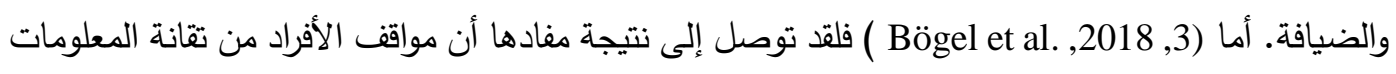

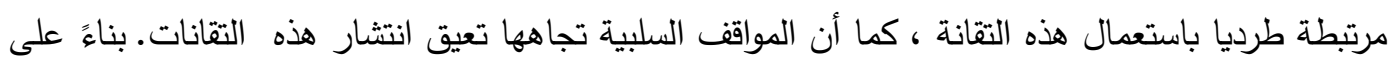
ماورد من نتائج أعلاه تقرر قبول الفرضية الثالثة. الفرضية الرابعة: تؤثر ثقة المستفيد بتقانة المعلومات تأثيراً معنوياً في انتثار تقانة المعلومات الصحية

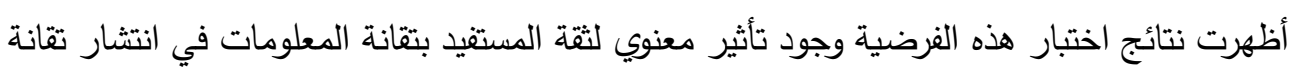

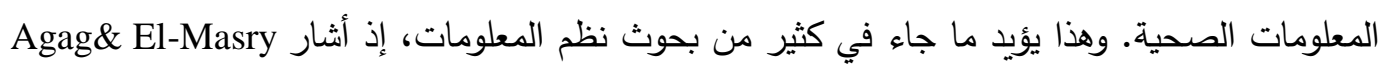

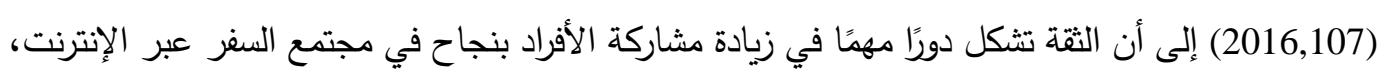

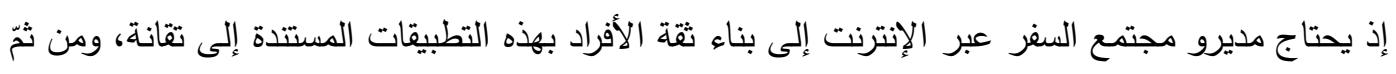

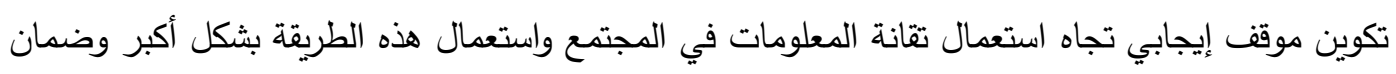

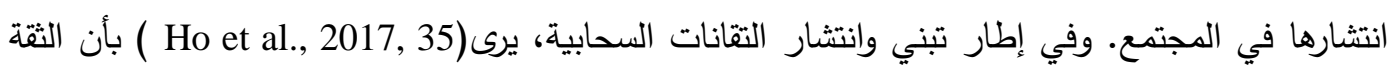

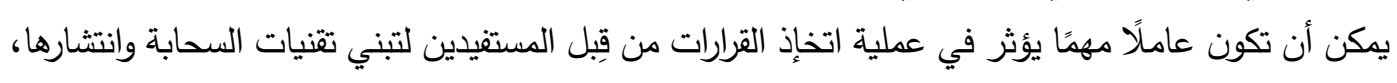

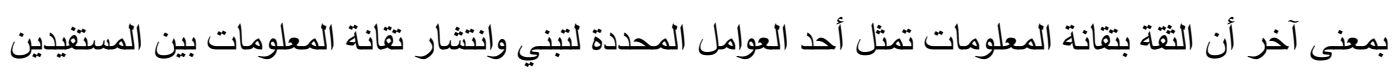
سواءاً كانوا أفراداً أو شركات. وتتاول (Kirs \& Bagchi, 2012, 413) موضوع الثقة من خلال مسح القيمة

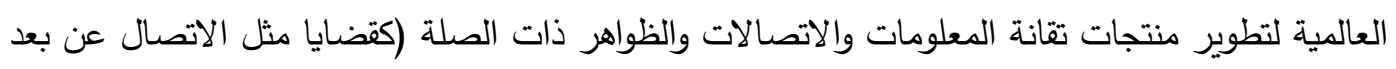
والخدمات التي تتطلب استعداد الحكومة الإكترونية) على المستوى الوطني، وكيف أثر معدل التغير في الثقة

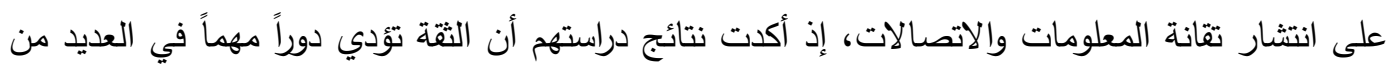

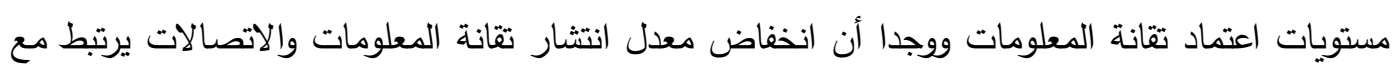
انخفاض معدل الثقة. واستتاداً إلى نتائج الاختبار الإحصائي لأنموذج الدراسة وبناءٍ على النتائج في أعلاه

$$
\text { فلقد تم قبول الفرضية الرابعة. }
$$

الفرضية الخامسة: تؤثر خصائص المستفيد تأثيراً معنوياً في انتثار تقانات المعلومات الصحية.

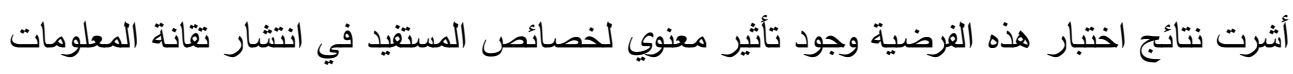

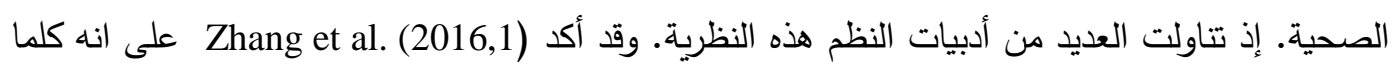

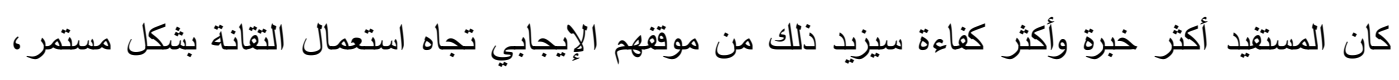
وهذا ما سينعكس فيما بعد على انتشار التقانة. وذكر Nambisa et al. (1999, 385) أن امتلاك المستفيد لبعض الخصائص مثل الميل تجاه تقانة المعلومات وثقته بهذه التقانة وبإبداعاتها سيؤدي في النهاية إلى 
انتشار التطبيقات المبتكرة لتقانة المعلومات. وأوضح (Dhukaram et al. (2011, 483 أن اعتماد بعض نظام الرعاية الصحية والمستتدة إلى تقانة المعلومات لم يتم اعتمادها ولم تصل إلى مرحلة الانتشار بسبب نقص لفص

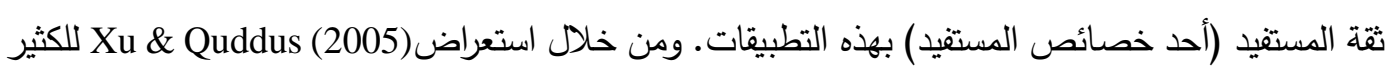
من الأدبيات في إطار علاقة خصائص المستغيد بانتثار تقانة المعلومات، توصل إلى أن خصائص المستثفيد

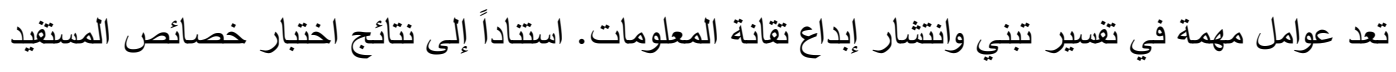

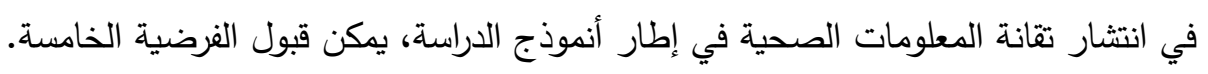
المحور السادس: الاستنتاجات والتوصيات

اولا: الاستنتاجات

ا ـ توافرت المؤشرات التي تثبت انتشار تقانة المعلومات الصحية في المستثفيات المبحوثة مثل الاستخدام المعمق لتقانة المعلومات، وذلك من خلال استخدام الكثير من التفاصيل المتعلقة بهذه التقانة والتي من تن

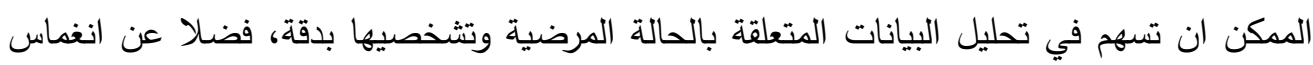

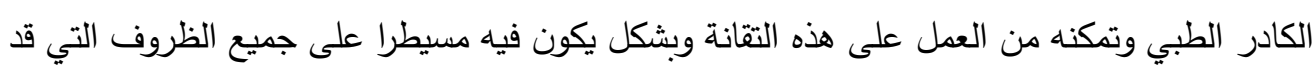

$$
\text { تؤدي الى الارباك. }
$$

r. اثتتت نتائج التحليل العاملي التوكيدي لانموذج القياس الخاص بالدراسة صدق وثبات الانموذج لقياس

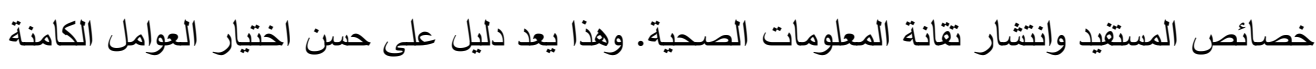
ومؤشرات القياس الخاصة بكل عامل، وانها جميعا تعمل في اطار متسق لقياس ما وظفت لاجل لاجل قياسه.

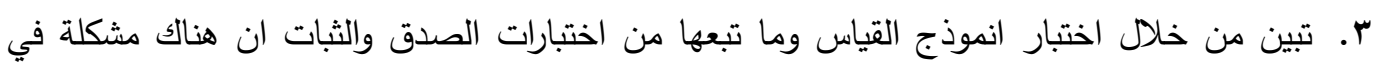
مؤشر القياس المسمى (استعمال التفاصيل) والذي استعمل في قياس انتثار التقانة، وكذلك الحال بالنسبة لمؤشر (جدارة التقانة) في العامل الكامن الثقة بتقانة المعلومات و والاستعمال بدون مساعدة) في قياس الكفاءة الذاتية. ء. استتاداً إلى معطيات الدراسة وما توصلت إليه من نتائج، يعد عامل الإبداع الثخصي أحد العوامل

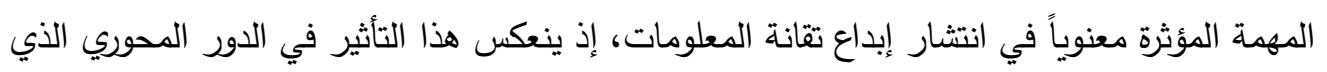

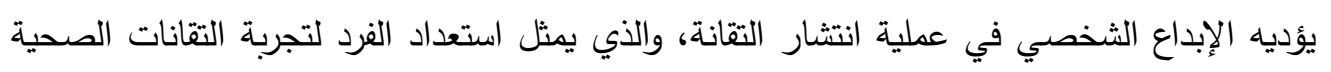

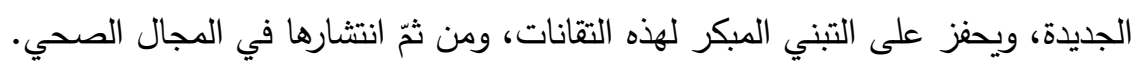

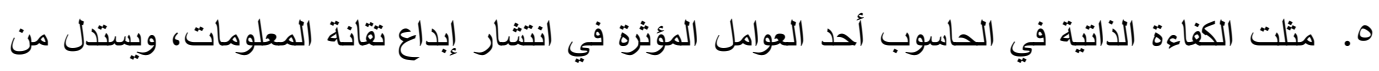

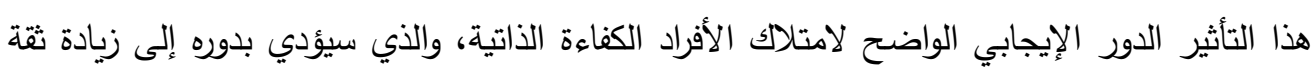

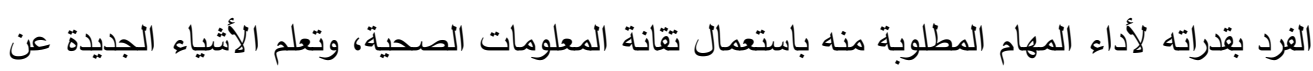

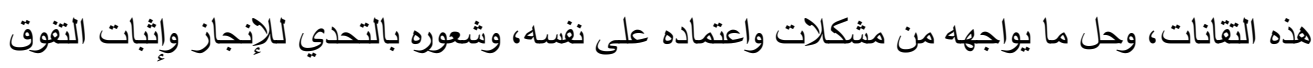
بالعمل. 
1. شكل موقف المستفيد تجاه تقانة المعلومات عاملاً مهماً من العوامل المحفزة لانتثار هذه التقانة المعلومات في المجال الصحي، إذ بينت النتائج بأن المواقف الإيجابية للمستفيد مرتبطة إيجابياً بانتشار

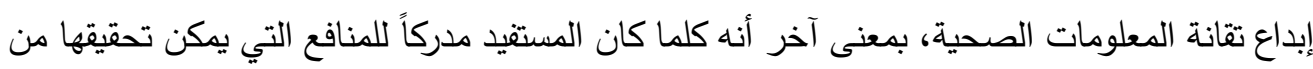

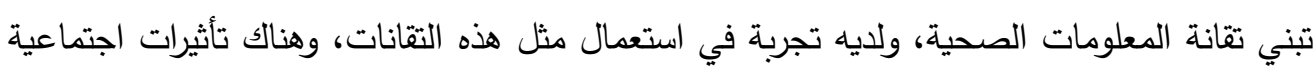

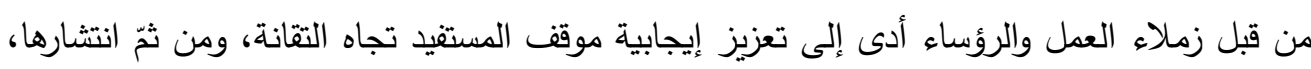

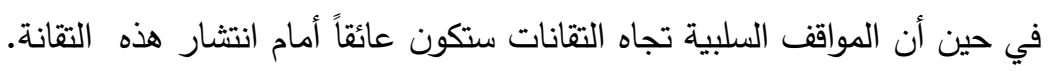

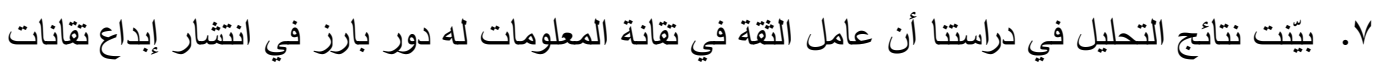

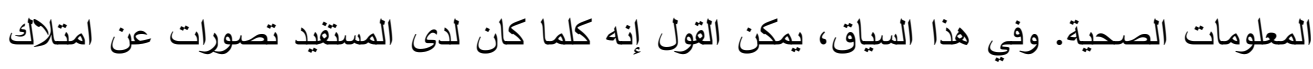
تقانة المعلومات الصحية خصائص تعود بالنفع عليه، في سياق عمله الصحي، زادئ زادت ثقته بهذه التقانة وبمخرجاتها، ومن ثمّ هذا ما يزيد من معدلات والانتثار . ثانيا: التوصيات

ا. توصي الدراسة الحالية بضرورة الاهتمام بالإبداع الثخصي والعمل على توفير المسوغات والعوامل كافة

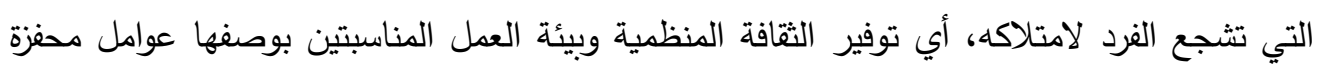
للإبداع الثخصي، وذلك لما تهيئه من ظروف تمكن الفرد من إظهار مهاراته، وحصول الفرد على دعم

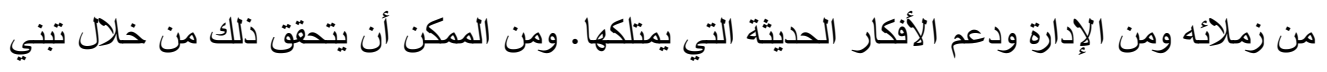
المستثفى لنظام حوافز خاص بالأفراد المبدعين وذلك من أجل تثجعيهم على إظهار قدار قدراتهم الإبداعية.

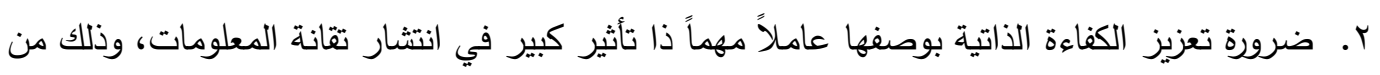

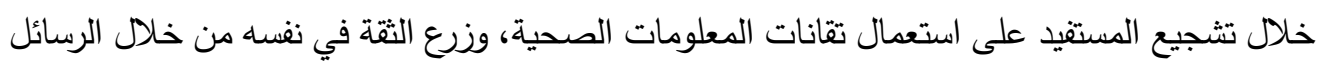

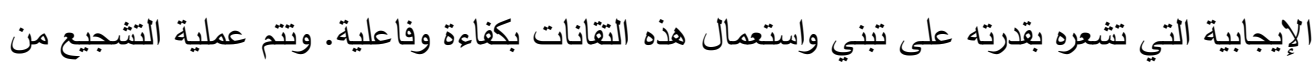

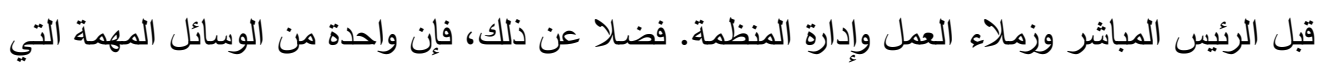

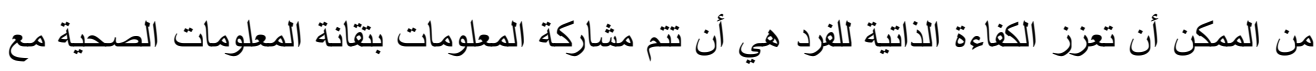
المستفيد وبخاصة فيما يتعلق بالجانب التقاني لهذه التقانة.

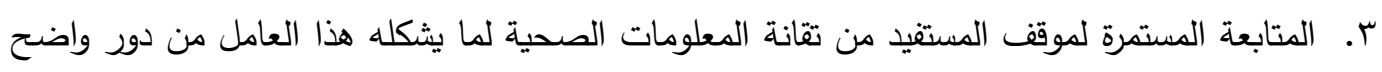

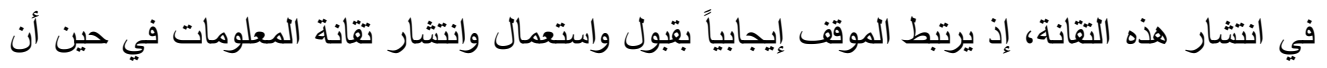

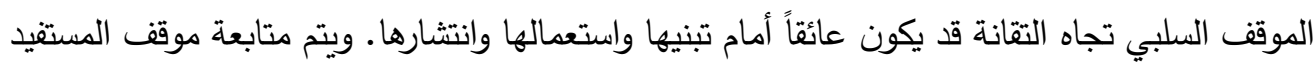

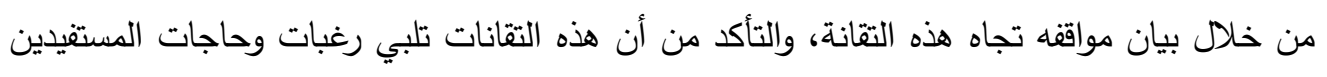
وأنها محدثة بما فيه الكفاية لمواكبة التطورات الحديثة في مجال العمل الصحي، وأنها تمتاز بسهولة الاستعمال وتمتاز نتائجها بالدقة والموثوقية.

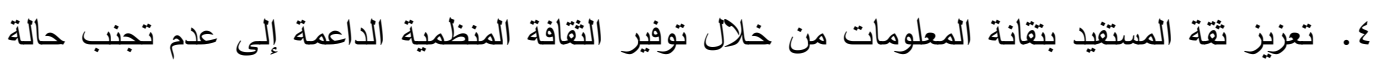

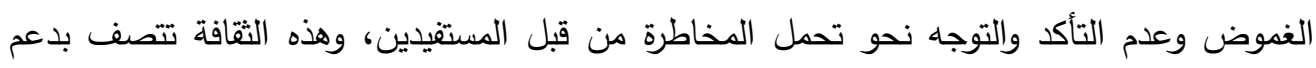




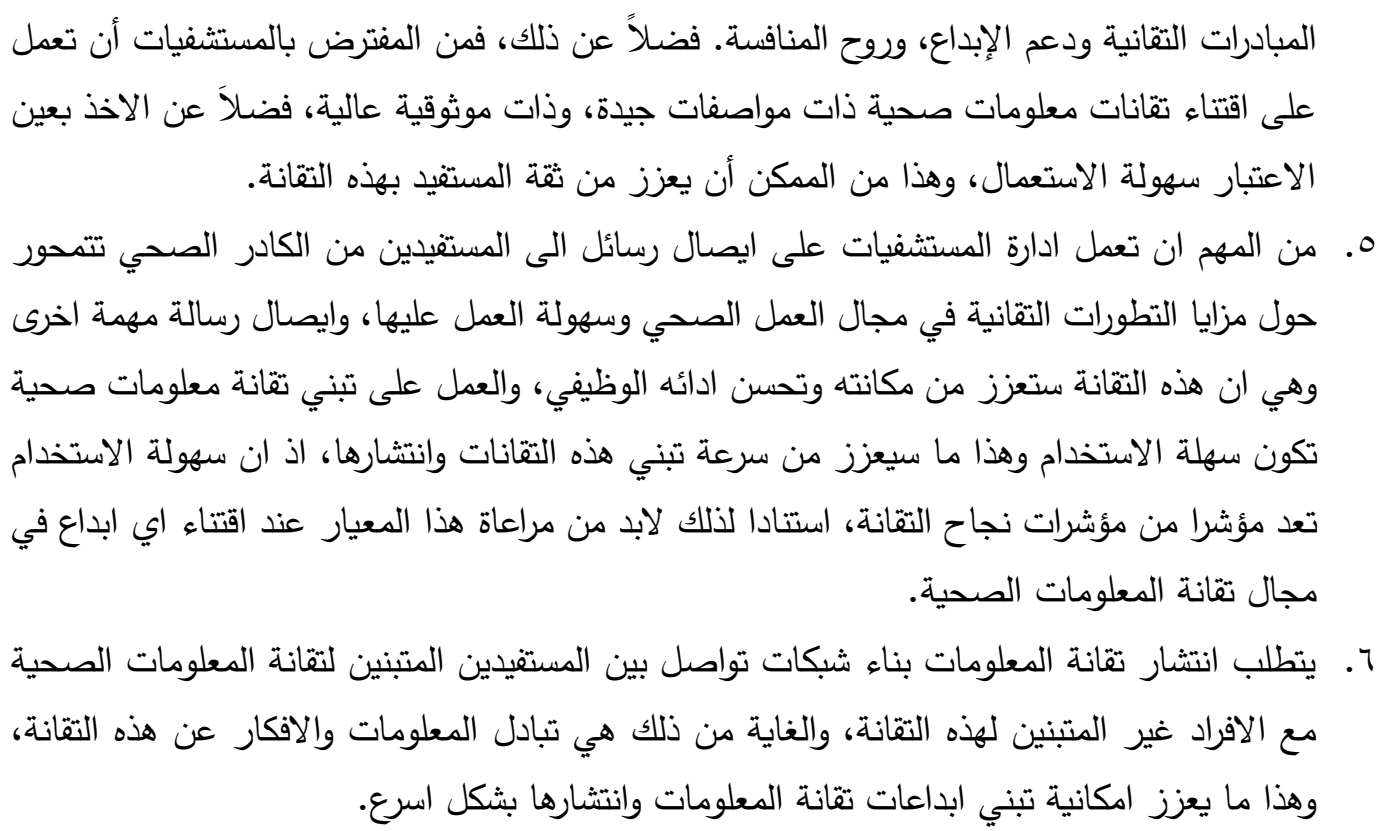

\section{Reference}

Alsabawy, Ahmed Younis (2019). Examining a Measurement Model of Management Information System Design Quality by Using Confirmatory Factor Analysis: Detailed Steps in the Context of an Empirical Study. Muthanna Journal of Administrative and Economic Sciences, (9), 2, 8-39.

Aluzir, Fozan Mohammed Ali (2018). Barriers of Adopting Medical Information Technology : A Survey Study of Medical Staff Opinions' In Kirkuk Hospitals. Higher Diploma Thesis, University of Mosul.

Al-Ali, Majid Mustfa \& Mohammed, Abdulmuttalb (2016). Self-efficacy and its relationship to the values and academic achievement of high school students in Kuwait. Journal of Educational Sciences, (3), 481-522.

Al-Faisal, Abdalmeer, (2017), Gratifications achieved via the Internet and its relationship to family separation. Journal of Literature Ink, (13). 551-584.

Al Sulaiman, Mohammed Ahmed (2018). Information Technology Innovation: A test of two measurement models of potential perceptions of using electronic banks. Higher Diploma Thesis. University of Mosul.

Agag, G., \& El-Masry, A. A. (2016). Understanding consumer intention to participate in online travel community and effects on consumer intention to purchase travel online and WOM: An integration of innovation diffusion theory and TAM with trust. Computers in human behavior, 60, 97-111.

Agarwal, R., \& Prasad, J. (1998). A conceptual and operational definition of personal innovativeness in the domain of information technology. Information systems research, 9(2), 204-215.

Anderson Jr. E. \& Lim, S.Y. (2016). Institutional Barriers against Innovation Diffusion: From The Perspective of Digital Health Startups.In:Proceedings of the 49th Hawaii International Conference on System Sciences. Computer Society, pp:33283337.

TANMIYAT AL-RAFIDAIN (P-ISSN: 1609-591X; E-ISSN: 2664-276X) تنمية الرافدين 
Bögel, P., Oltra, C., Sala, R., Lores, M., Upham, P., Dütschke, E., \& Wiemann, P. (2018). The role of attitudes in technology acceptance management: Reflections on the case of hydrogen fuel cells in Europe. Journal of Cleaner Production, 188, 125135.

Brown, T.A., \& Moore, M.T. (2012). Confirmatory factor analysis. In R. H. Hoyle (Ed.), Handbook of structural equation modeling (pp. 361-379. The Guilford Press. New York.USA

Compeau, D. R., \& Higgins, C. A. (1995). Computer self-efficacy: Development of a measure and initial test. MIS quarterly, 189-211.

Cruz-Cárdenas, J., Zabelina, E., Deyneka, O., Guadalupe-Lanas, J., \& Velín-Fárez, M. (2019). Role of demographic factors, attitudes toward technology, and cultural values in the prediction of technology-based consumer behaviors: A study in developing and emerging countries. Technological Forecasting and Social Change, 149, 119768.

Dhukaram, A. V., Baber, C., Elloumi, L., van Beijnum, B. J., \& De Stefanis, P. (2011, May). End-user perception towards pervasive cardiac healthcare services: Benefits, acceptance, adoption, risks, security, privacy and trust. In 2011 5th International Conference on Pervasive Computing Technologies for Healthcare (PervasiveHealth) and Workshops (pp. 478-484). IEEE.

Gefen, D., \& Straub, D. (2005). A practical guide to factorial validity using PLS Graph: Tutorial and annotated example. Communications of the Associatio for Information Systems, 16, 91-109.

Gefen, D., Karahanna, E., \& Straub, D. W. (2003). Trust and TAM in online shopping: an integrated model. MIS quarterly, 27(1), 51-90.

Haggstrom, D. A., Lee, J. L., L. Dickinson, S., Kianersi, S., Roberts, J. L., Teal, E., \& Rawl, S. M. (2019). Rural and Urban Differences in the Adoption of New Health Information and Medical Technologies. The Journal of Rural Health (paper under publish).

Hair, J.F., Black, W.C., Babin, B., \& Anderson, R.E. (2014). Multivariate Data Analysis (7th ed.). United Kingdom: Pearson Education Limited.

Haug, M., Gewald, H., \& Rockmann, R. (2018). Grandma's New Tablet-The Role of Mobile Devices in Trying to Innovate in IT. Procedia Computer Science, 141, 460465.

Ho, S. M., Ocasio-Velázquez, M., \& Booth, C. (2017). Trust or consequences? Causal effects of perceived risk and subjective norms on cloud technology adoption. Computers \& Security, 70, 581-595.

Ivanov, S., Webster, C., \& Garenko, A. (2018). Young Russian adults' attitudes towards the potential use of robots in hotels. Technology in Society, 55, 24-32.

Jackson, J. D., Mun, Y. Y., \& Park, J. S. (2013). An empirical test of three mediation models for the relationship between personal innovativeness and user acceptance of technology. Information \& Management, 50(4), 154-161.

Jacobs, R. J., Caballero, J., Parmar, J., \& Kane, M. N. (2019). The role of self-efficacy, flexibility, and gender in pharmacy students' health information technology readiness. Currents in Pharmacy Teaching and Learning, 11(11), 1103-1110.

Justinia, T. (2017). The UK's National Programme for IT: Why was it dismantled?. Health services management research, 30(1), 2-9.

Kirs, P., \& Bagchi, K. (2012). The impact of trust and changes in trust: A national comparison of individual adoptions of information and communication

TANMIYAT AL-RAFIDAIN (P-ISSN: 1609-591X; E-ISSN: 2664-276X) تنمية الرافدين 
technologies and related phenomenon. International Journal of Information Management, 32(5), 431-441.

Kline, R.B. (2016). Principles and practice of structural equation modeling (4th ed.). New York: The Guilford Press.

Lee, H. H., \& Chang, E. (2011). Consumer attitudes toward online mass customization: An application of extended technology acceptance model. Journal of ComputerMediated Communication, 16(2), 171-200.

Mahat, J., Ayub, A. F. M., \& Luan, S. (2012). An assessment of students' mobile selfefficacy, readiness and personal innovativeness towards mobile learning in higher education in Malaysia. Procedia-Social and Behavioral Sciences, 64, 284-290.

McKnight, D. H., Choudhury, V., \& Kacmar, C. (2002). Developing and validating trust measures for e-commerce: An integrative typology. Information systems research, 13(3), 334-359.

McLean, G., Osei-Frimpong, K., Al-Nabhani, K., \& Marriott, H. (2020). Examining consumer attitudes towards retailers'm-commerce mobile applications-An initial adoption vs. continuous use perspective. Journal of Business Research, 106, 139157.

Mun, Y. Y., \& Hwang, Y. (2003). Predicting the use of web-based information systems: self-efficacy, enjoyment, learning goal orientation, and the technology acceptance model. International journal of human-computer studies, 59(4), 431-449.

Nambisan, S., Agarwal, R., \& Tanniru, M. (1999). Organizational mechanisms for enhancing user innovation in information technology. MIS quarterly, 365-395.

Reychav, I., Beeri, R., Balapour, A., Raban, D. R., Sabherwal, R., \& Azuri, J. (2019). How reliable are self-assessments using mobile technology in healthcare? The effects of technology identity and self-efficacy. Computers in Human Behavior, 91, 52-61.

Schumacker, R. E. \& Lomax, R. G. (2010). A beginner's guide to structural equation modeling. Third edition, Routledge, Taylor \& Francis Group, New York. U.S.A.

Sørebø, A. M., Sørebø, Ø., \& Sein, M. K. (2008). The influence of user involvement and personal innovativeness on user behavior. International Journal of Human and Social Sciences, 3(5), 326-331.

Thakur, R., Angriawan, A., \& Summey, J. H. (2016). Technological opinion leadership: The role of personal innovativeness, gadget love, and technological innovativeness. Journal of Business Research, 69(8), 2764-2773.

Turja, T., Rantanen, T., \& Oksanen, A. (2019). Robot use self-efficacy in healthcare work (RUSH): development and validation of a new measure. AI \& SOCIETY, 34(1), 137-143.

Wilson, K., \& Khansa, L. (2018). Migrating to electronic health record systems: A comparative study between the United States and the United Kingdom. Health Policy (Article under publish).

Xu, J., \& Quaddus, M. (2005). Adoption and diffusion of knowledge management systems: an Australian survey. Journal of Management Development, 24, (4), 335-361.

Yarar, İ., \& Karabacak, K. (2015). 8th grade students' attitude towards technology. Procedia-Social and Behavioral Sciences, 174, 2051-2060.

Zhang, T., Siebers, P. O., \& Aickelin, U. (2016). Simulating user learning in authoritative technology adoption: An agent based model for council-led smart meter deployment planning in the UK. Technological Forecasting and Social Change, $106,74-84$.

TANMIYAT AL-RAFIDAIN (P-ISSN: 1609-591X; E-ISSN: 2664-276X) تنمية الرافدين 